\begin{tabular}{c} 
ORNL \\
CENTRAL FILES NUMBER \\
ORNL $/$ CF $-01 / 24$ \\
\hline
\end{tabular}

DATE: $\quad$ May 8, 2001

SUBJECT: Semi-annual Technical Progress Report of the Radioisotope Power System Materials Production and Technology Program Tasks for September 2000 through March 2001

TO: Distribution

FROM: J.P. Moore D.P.Moore

The enclosed report covers technical progress on the Radioisotope Power System Program for the first six months of Fiscal Year 2001. This report is one of a series to inform the Office of Space and Defense Power Systems, U.S. Department of Energy, and their contractors of accomplishments by the Oak Ridge National Laboratory which is operated by UT-Battelle. If you have any questions or require further clarification on any topic, please contact me at Building 4508, Mail Stop 6079 or call me at 865-574-8258.

JPM:smw 


\title{
SEMI-ANNUAL TECHNICAL PROGRESS REPORT OF RADIOISOTOPE POWER SYSTEM MATERIALS PRODUCTION AND TECHNOLOGY PROGRAM TASKS FOR SEPTEMBER 1, 2000 THROUGH MARCH 31, 2001
}

\author{
Prepared for Department of Energy \\ Office of Space and Defense Power Systems \\ under Budget and Reporting Classification \\ AF 7010200 , AF 706000 , and AF 7030000
}

by

Radioisotope Power System Program

Metals and Ceramics Division

Oak Ridgé National Laboratory

Oak Ridge National Laboratory

Oak Ridge, Tennessee 37831-6080

operated by UT-Battelle, LLC

for the

U.S. Department of Energy

Contract DE-AC05-00OR22725 
This page intentionally blank 


\section{CONTENTS}

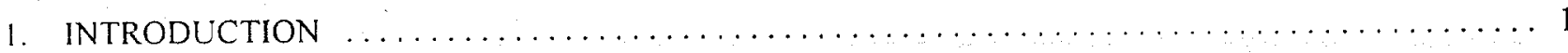

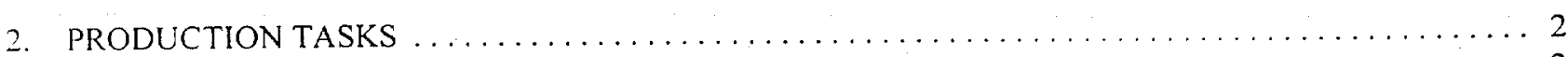

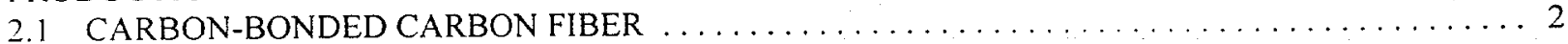

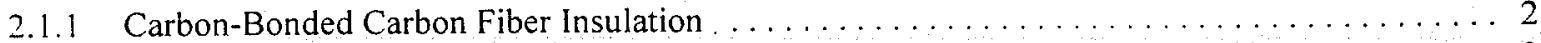

2.2 IRIDIUM-ALLOY BLANK AND FOIL PRODUCTION $\ldots \ldots \ldots \ldots \ldots \ldots \ldots \ldots \ldots \ldots \ldots$

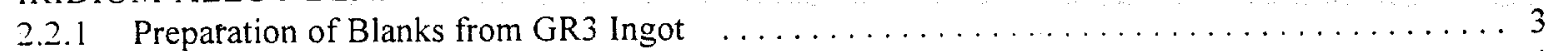

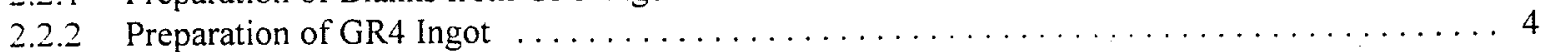

2.2.3 Glow Discharge Mass Spectroscopy $\ldots \ldots \ldots \ldots \ldots \ldots \ldots \ldots \ldots \ldots \ldots \ldots \ldots \ldots$

2.2.4 Samples for Johns Hopkins University, Applied Physics Laboratory . . . . . . . . . . . 5

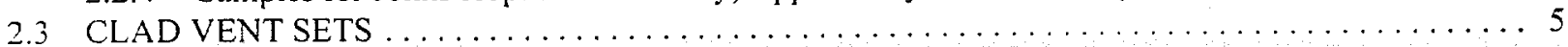

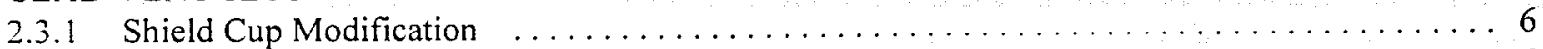

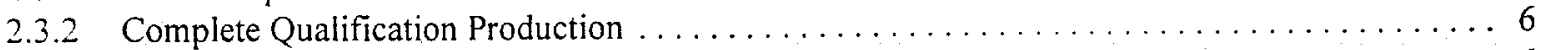

2.3.3 Procedure 5 FQ CVS with Integral Weld Shield and Ship to LANL $\ldots \ldots \ldots \ldots \ldots \ldots$

2.3.4 Assess the Effect on Vent Notch Width on Clad Girth Weld on CVS with

Notch Combinations $B$ and $C$ Containing Integral Weld Shields $\ldots \ldots \ldots \ldots \ldots \ldots$

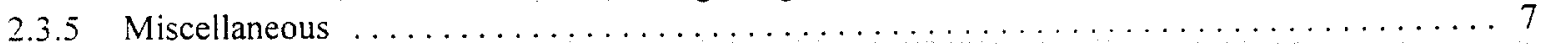

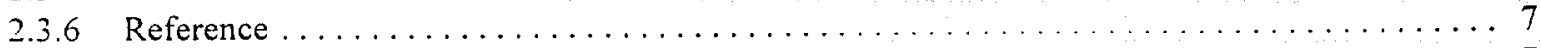

2.4 IRIDIUM POWDER AND INVENTORY MANAGEMENT $\ldots \ldots \ldots \ldots \ldots \ldots \ldots \ldots \ldots \ldots \ldots$

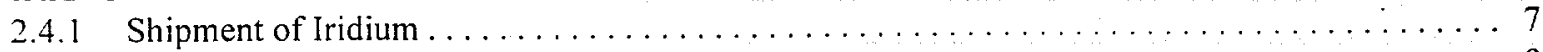

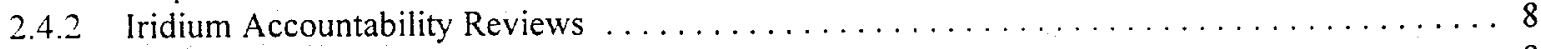

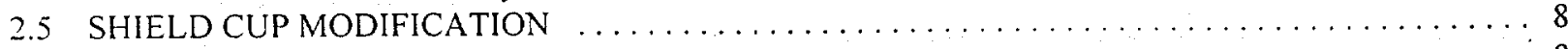

2.5.1 Establishing Capability for Installing IWS $\ldots \ldots \ldots \ldots \ldots \ldots \ldots \ldots \ldots \ldots \ldots \ldots$

2.5.2 Processing of LANL Returns and Qualification Production Assemblies $\ldots \ldots \ldots \ldots \ldots \ldots 8$

3. BASE TECHNOLOGY PROGRAM AND TECHNICAI. SUPPORT ACTIVITIES $\ldots \ldots \ldots \ldots \ldots . . .9$

3.1 TECHNICAL SUPPORT FOR THE ARPS AMTEC CELL DEVELOPMENT $\ldots \ldots \ldots \ldots \ldots \ldots 9$

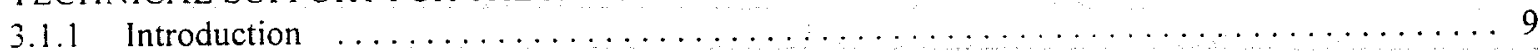

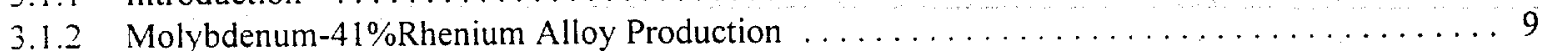

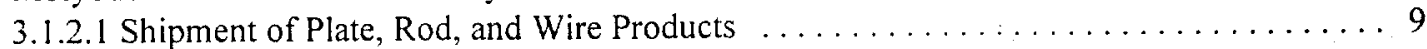

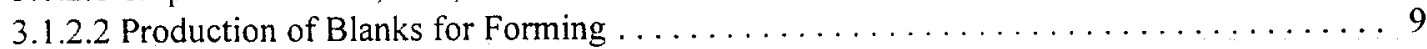

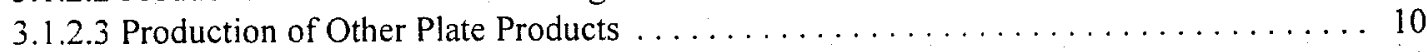

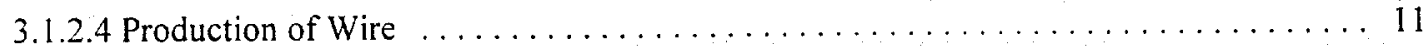

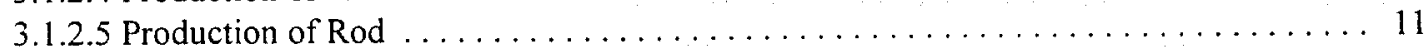

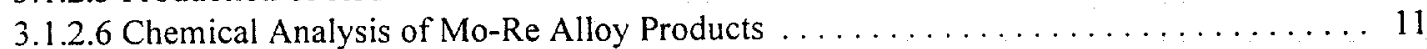

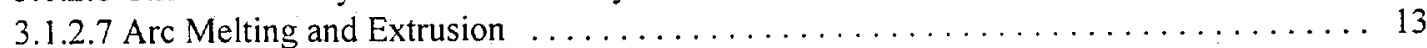

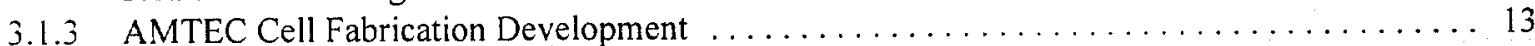

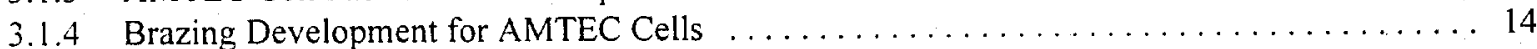

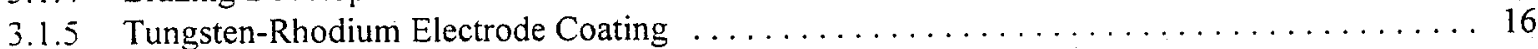

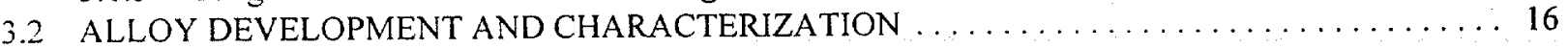

3.2.1 Oxygen Compatibility of Ce-Doped Iridium Alloys at $1330^{\circ} \mathrm{C}$ in an Oxygen

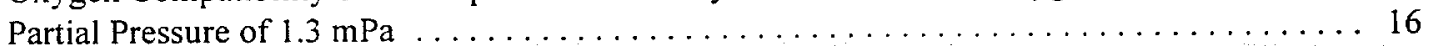

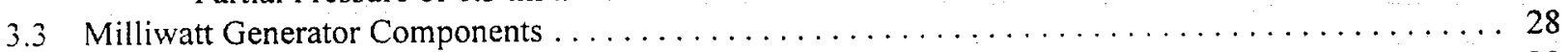

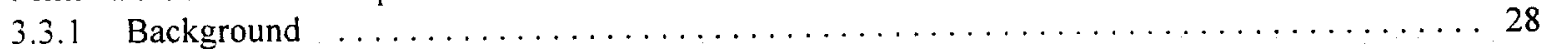

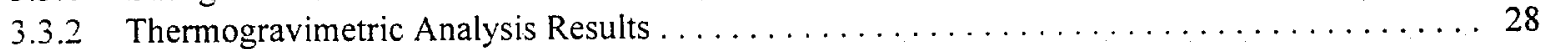

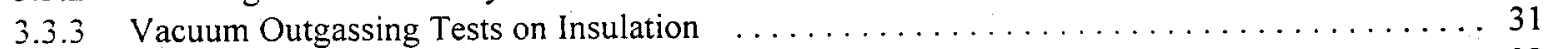

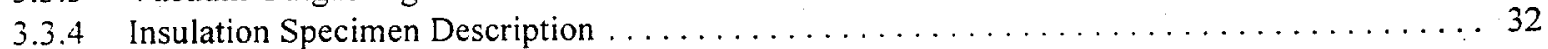

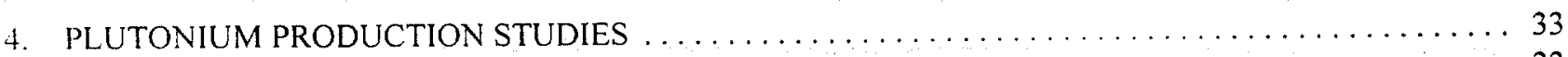

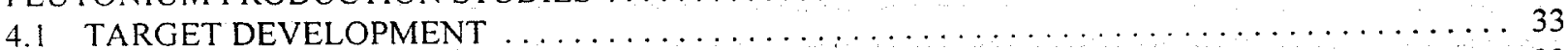

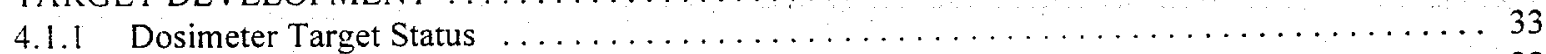

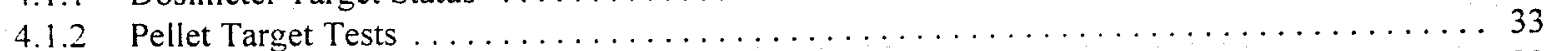

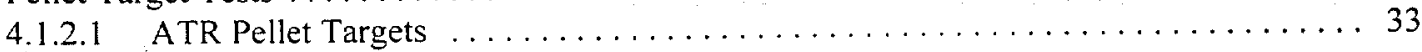


4.1.2.2 HFIR Pellet Targets $\ldots \ldots \ldots \ldots \ldots \ldots \ldots \ldots \ldots \ldots \ldots \ldots \ldots \ldots \ldots \ldots \ldots \ldots$

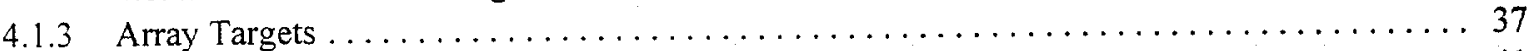

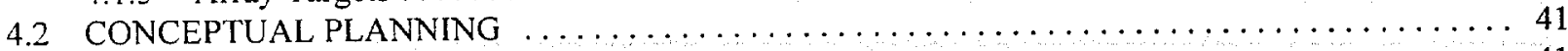

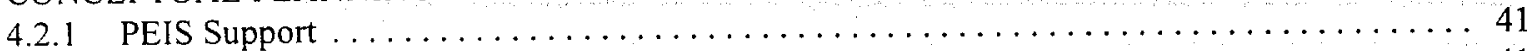

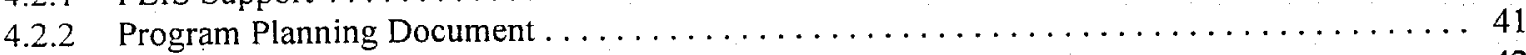

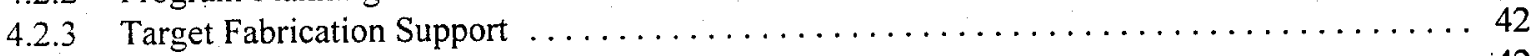

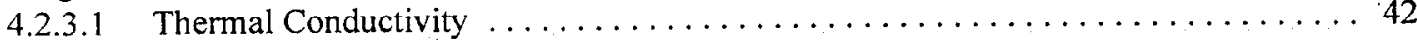

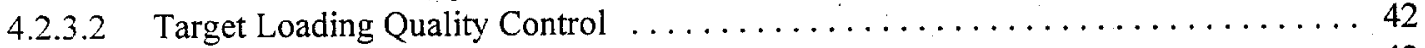

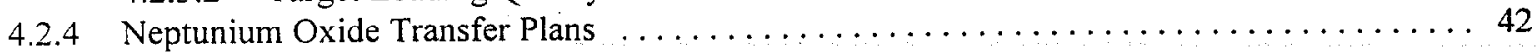




\section{INTRODUCTION}

The Office of Space and Defense Power Systems of the Department of Energy (DOE) provides Radioisotope Power Systems (RPS) for applications where conventional power systems are not feasible. For example, radioisotope thermoelectric generators were supplied by the DOE to the National Aeronautics and Space Administration for deep space missions including the Cassini Mission launched in October of 1997 to study the planet Saturn. The Oak Ridge National Laboratory (ORNL) has been involved in developing materials and technology and producing components for the DOE for more than three decades. For the Cassini Mission, for example, ORNL was involved in the production of carbon-bonded carbon fiber (CBCF) insulator sets, iridium alloy blanks and foil, and clad vent sets (CVS) and weld shields (WS).

This report has been divided into three sections to reflect program guidance from the Office of Space and Defense Power Systems for fiscal year (FY) 2001. The first section deals primarily with maintenance of the capability to produce flight quality (FQ) $\mathrm{CBCF}$ insulator sets, iridium alloy blanks and foil, CVS, and WS. In all three cases, production maintenance is assured by the manufacture of limited quantities of FQ components. The second section deals with several technology activities to improve the manufacturing processes, characterize materials, or to develop technologies for new radioisotope power systems. The last section is dedicated to studies related to the production of ${ }^{238} \mathrm{Pu}$. 


\section{PRODUCTION TASKS}

\subsection{CARBON-BONDED CARBON FIBER}

The goal of this effort is to maintain production capability for $\mathrm{CBCF}$ insulation sets. These are produced under closely controlled conditions and stringent quality assurance procedures to ensure compliance with material specifications at each step in the production process, from the handling of raw materials to finished parts. Dedicated facilities for $\mathrm{CBCF}$ production remain in the Carbon and Insulation Materials Technology Laboratory. Periodic exercise of production activities is performed to assure that the processes can be successfully executed and to verify personnel competencies and adequacy of training, equipment, and procedures.

Our goal this year includes: (1) complete the characterization of CBCF sleeves produced in FY 2000, (2) produce and certify five new sets of flight quality $\mathrm{CBCF}$ sleeves and disks, (3) complete a preliminary assessment of a new resin for the production of $\mathrm{CBCF}$ and (4) complete a draft video of $\mathrm{CBCF}$ production and qualification tasks.

\subsubsection{Carbon-Bonded Carbon Fiber Insulation}

$\mathrm{CBCF}$ production and characterization tasks are running smoothly in the current fiscal year. A revised procedure for the determination of sulfur in $C B C F$ will allow final qualification of $C B C F$ produced in $F Y 2000$. Videotaping of CBCF production activities continues. The balance of this report will address the results on pre-qualifying a new resin for CBCF production.

One molding run of nine CBCF sleeves requires $227 \mathrm{gm}$ of Durez 22352 phenolic resin. One plate run for the production of about $200 \mathrm{CBCF}$ disks requires $252 \mathrm{gm}$ of resin. Durez 22352 resin was once a commercial product of the Durez Division of Occidental Chemical Corporation, but it is no longer in production. The RPS program inventory of this resin is sufficient for approximately 20 additional molding runs, i.e., 180 insulation sets.

In view of the limited supply of qualified resin, steps were taken beginning in FY 2000 to identify a suitable replacement for Durez 22352 resin. Oxy Chem Durez of Canada has replaced the resin with Durez 5034 resin. A comparison of the manufacturer's specification for these two resins is given in Table 1. All attributes are nominally similar. Given the longer cure time required for $\mathrm{CBCF}$ production, the time required in the accelerated cure test for Durez 5034 resin appears to be acceptable. CBCF procedure MET-CER-SOP-32 Rev. 6 calls for the following cure cycle: 3 hrs. @ $80^{\circ} \mathrm{C} / 3$ hrs. @ $100^{\circ} \mathrm{C} / 12$ hrs. @ $130^{\circ} \mathrm{C}$.

Table 1

\begin{tabular}{|l|l|l|l|}
\hline \multicolumn{1}{|c|}{ Average Property } & \multicolumn{1}{|c|}{ Test Method* } & \multicolumn{1}{c|}{ Durez 22352 } & \multicolumn{1}{c|}{ Durez 5034 } \\
\hline \hline Cure @ $165^{\circ} \mathrm{C}(\mathrm{s})$ & DCT \#162A & 30 & 45 \\
\hline Inclined Plate Flow (mm) & DCT \#351 & 30 & 33 \\
\hline $\begin{array}{l}\text { Screen Test } \\
(\% \text { on 200 mesh) }\end{array}$ & DCT \#7 & 1 max & 3 max \\
\hline
\end{tabular}

* Durex Control Test Method

\section{Particle Sizes}

Both resins were supplied as finely pulverized powders. Particle size distributions were determined using a Laser Scattering Particle Size Analyzer. The mean particle size for both resins was in the range of 20 to 30 microns with very similar distribution of particle sizes about the mean. 


\section{Char Yield}

Small samples of Durez 5034 resin and Durez 22352 resin were carbonized at $650^{\circ} \mathrm{C}$ for a period of 12 hours in a nitrogen atmosphere. The char yield was $59.2 \%$ and $60.0 \%$, respectively.

\section{Vacuum Molding and Machining}

One molding run of CBCF sleeves was made with the 5034 resin. All characteristics of the new resin were identical to Durez 22352 resin in slurry preparation and molding. Machining characteristics were also indistinguishable.

\section{Chemical Analysis}

Samples of CBCF produced with the new resin were submitted for chemical analysis in accordance with Procedure ACMM-4 0203, Rev. A. The impurity levels were all within specification for flight quality insulation and were generally better than CBCF produced with the established resin.

\section{Microstructure and Density}

Scanning Electron Micrographs shown in Figure X illustrate that CBCF produced with Durez 5034 is indistinguishable from the flight quality material. The density of CBCF produced with Durez 5034 resin was identical $(\mathrm{P}=.217 \mathrm{~g} / \mathrm{cm} 3)$ to typical flight quality material and within the specified range of 0.20 to $0.26 \mathrm{~g} / \mathrm{cm}^{3}$. X-ray radiography inspection performed in accordance with Procedure MET-NDT-CBCF-RAD- Rev. 3 was performed on CBCF sleeves produced with Durez 5034. All passed flight quality requirements.

\section{Compressive Strength}

The strength specification requires a compressive strength greater than or equal to $75 \mathrm{psi}$ at $5 \%$ strain. The compressive strength achieved with the new resin was $85 \mathrm{psi}$ which is within specification but less than the 110 psi typical for CBCF produced with the old resin.

\section{Thermal Conductivity}

The CBCF specification requires a thermal conductivity less than $.086 \mathrm{~W} / \mathrm{m} \mathrm{K}$. The thermal conductivity of CBCF produced with Durez 5034 resin was $0.043 \mathrm{~W} / \mathrm{m}$ which is better than the typical value of .057 achicved with the qualified resin.

\section{Conclusion}

Durez 5034 resin appears to be an acceptable replacement for Durez 22352 resin for the production of CBCF. This resin should be established for use in the production of flight quality $\mathrm{CBCF}$ through a more rigorous qualification program under future production maintenance activities.

\subsection{IRIDIUM-ALLOY BLANK AND FOIL PRODUCTION}

The goals for this activity are to produce flight-quality blanks and foil under full configuration control and to supply materials needed for CVS demonstration and production maintenance activities. During the first half of FY 2001 six sheets from the G3 ingot were rolled and electro-discharge machined to produce 35 blanks. Preparation of the GR4 ingot electrode was begun. Efforts to qualify an outside service provider of chemical analysis on iridium and molybdenum alloys were initiated.

\subsubsection{Preparation of Blanks from GR3 Ingot}

The G3 extruded bar segments G3-1 through G3-6 were cleaned, rolled, and stress relieved to produce six sheets for blank production. The sheets have been electro-discharge machined to produce 35 blanks. The blanks will be ground, cleaned, and inspected during the second half of FY2001 to produce 30 flight-quality blanks for storage. 


\subsubsection{Preparation of GR4 Ingot}

Production of the GR4 recycle ingot was initiated. Iridium alloy recycle materials for ingots G1, G2 and G3, with a total weight of $15 \mathrm{~kg}$ was cleaned and prepared for remelting. Melting and drop-casting of electrode segments for the GR4 ingot was begun and is approximately $80 \%$ complete. The GR4 electrode of $11 \mathrm{~kg}$ will be assembled and electron beam welded, vacuum arc remelted and extruded during the current fiscal year to permit the preparation of blanks during FY 2002.

\subsubsection{Glow Discharge Mass Spectroscopy}

We need to qualify another glow discharge mass spectrograph for chemical analysis of iridium alloy blanks, foil, and cups and iridium powder because the availability of the instruments at ORNL and $Y-12$ is uncertain. Sample iridium alloy materials were sent to outside service providers (Shiva Technologies, Inc., Syracuse NY and Engelhard, Carteret $\mathrm{NJ}$ ) in order to determine the capabilities of those organizations. These service providers were chosen because of previous experience in the analysis of iridium materials for other customers. The samples submitted consisted of the iridium alloy reference materials currently used for analysis at ORNL. These two reference materials have been extensively characterized. The first, identified as G1-10, is a reference for the three alloying elements in the DOP-26 composition: W, Th, and Al. The second, identified as RS10-9-1, is a reference for 15 metallic impurity elements in iridium. One sample of each reference material was analyzed by Shiva Technologies in July 2000 and one sample of each in December 2000. One sample of each reference material was analyzed by Engelhard in December 2000. Evaluation of the results from Shiva indicates that without any information given to that service provider, the analyses for all elements are almost invariably within a factor of two of the values determined by ORNL. The results of the analyses for individual elements obtained from the same reference material at different times also varies by as much as a factor of two. The variation is considered acceptable for an analysis not corrected by used of standards. The results of uncorrected analyses from Engelhard show agreement to within a factor of two for most elements but with some much larger discrepancies for aluminum and several important impurity elements.

The data has been analyzed using a method of correction equivalent to that in the existing procedure for iridium alloy analysis at ORNL. The composition of the alloying elements in the RS10-9-1 was corrected using the G1-10 reference material analyzed on the same day. The composition of important impurity elements in the G1-10 was corrected using the RS 10-9-1 reference material analyzed on the same day. The corrected Shiva analyses for alloying elements in the RS10-9-1 shown in Table 1 are in good agreement with the reference values. The corrected Engelhard result for aluminum is rather low. The corrected analyses for impurity elements in the G-1-10 shown in Table 2 are in good agreement with the reference values. Several minor impurity elements, with concentrations in the range of 0.1 to 1 ppm, for which no correction to a reference value is possible, are listed in Table 3 with analyzed contents from ORNL and the service providers. Again the agreement is quite good. The differences between the corrected values for the service provider and the reference values are equivalent to $10 \%$ of the specification range or less, which is acceptable. The corrected results from Shiva are generally in better agreement with the ORNL reference values than those from Engelhard.

Table 1. Comparison of Corrected Analysis from Service Providers of Alloying Elements in RS-10-9-1 Reference Material

\begin{tabular}{|c|r|r|r|r|}
\hline \multirow{2}{*}{ Element } & \multicolumn{3}{|c|}{ Content, ppm by Weight } & \multirow{2}{*}{ Engelhard } \\
\cline { 2 - 4 } & \multirow{2}{*}{ Reference } & \multicolumn{2}{|c|}{ Shiva } & December \\
\cline { 2 - 5 } & & August & 52 & 38 \\
$\mathrm{Al}$ & 53 & 56 & 3240 & 3010 \\
W & 3230 & 3190 & 62 & 58 \\
\hline \hline $\mathrm{Th}$ & 55 & 59 & \\
\hline
\end{tabular}


Table 2. Comparison of Corrected Analysis from Service Providers of Alloying Elements in RS-10-9-1 Reference Manual

\begin{tabular}{|c|c|c|c|c|}
\hline \multirow{2}{*}{ Element } & \multicolumn{3}{|c|}{ Content, ppm, by Weight } \\
\cline { 2 - 4 } & \multirow{2}{*}{ Reference } & \multicolumn{2}{|c|}{ Shiva } & \multirow{2}{*}{ Engelhard } \\
\cline { 2 - 4 } & & August & December & \\
\hline \hline $\mathrm{Si}$ & 1.8 & 2.0 & 1.5 & 2.2 \\
$\mathrm{Ti}$ & 1.9 & 1.5 & 1.9 & 3.0 \\
$\mathrm{Cr}$ & 0.2 & 0.2 & 0.2 & 0.3 \\
$\mathrm{Fe}$ & 0.8 & 0.8 & 0.6 & 1.4 \\
$\mathrm{Ni}$ & 0.1 & 0.2 & 0.1 & 0.3 \\
$\mathrm{Cu}$ & 0.4 & 0.4 & 0.3 & 0.5 \\
$\mathrm{Nb}$ & 0.3 & 0.2 & 0.3 & 0.4 \\
$\mathrm{Mo}$ & 1.0 & 0.9 & 0.9 & 4.4 \\
$\mathrm{Ru}$ & 17.0 & 14.6 & 15.9 & 17.0 \\
$\mathrm{Rh}$ & 3.0 & 3.3 & 3.1 & 4.7 \\
$\mathrm{Re}$ & $<0.5$ & 0.1 & 0.0 & 0.1 \\
$\mathrm{Os}$ & $<0.5$ & 0.5 & 0.2 & 0.3 \\
$\mathrm{Pt}$ & 3.5 & 3.2 & 3.1 & 4.1 \\
\hline
\end{tabular}

Table 3. Comparison of Minor Impurity (<1ppm) Analyses Made Without Correction for Standard

\begin{tabular}{|c|c|c|c|c|c|c|}
\hline & \multicolumn{3}{|c|}{ G1-10 (ppm by weight) } & \multicolumn{3}{c|}{ RS10-9 (ppm by weight) } \\
\hline & ORNL & Shiva & Engelhard & ORNL & Shiva & Engelhard \\
\hline \hline $\mathrm{V}$ & 0.05 & 0.06 & 0.3 & 0.2 & 0.33 & 0.7 \\
$\mathrm{Mn}$ & 0.02 & 0.02 & 0.07 & 0.2 & 0.23 & 0.5 \\
$\mathrm{Co}$ & 0.006 & 0.007 & 0.04 & 0.12 & 0.13 & 0.35 \\
$\mathrm{Y}$ & 0.06 & 0.04 & 0.1 & 0.05 & 0.04 & 0.07 \\
\hline
\end{tabular}

A plan for development of a procedure for analysis of iridium materials by an outside service provider was drafted. The plan includes surface analysis of sheet material, and bulk analysis of sheet material, foil, cup d-test specimens and powder analyses.

\subsubsection{Samples for Johns Hopkins University, Applied Physics Laboratory}

Preparation of samples from iridium alloy blanks was begun for flame impingement testing at Johns Hopkins University, Applied Physics Laboratory. Samples of 1 " square were machined from 3 iridium alloy blanks and these were sent with two cups for flame impingement testing at Johns Hopkins University, Applied Physics Laboratory.

\subsection{CLAD VENT SETS}

The goal of this activity is to produce flight quality clad vent sets (CVS) for inventory, test hardware and to maintain the production capability. 


\subsubsection{Shield Cup Modification}

Weld shields were welded into the $59 \mathrm{FQ}$ and 9 Engineering Use (EU) shield cups returned from Los Alamos National Laboratory (LANL) as well as all 14 Qualification Production shield cups. Rewelding was required on 15 out of the 82 total (or $18 \%$ of) shield cup assemblies (SCAs). Rewelding was required to repair minor grain boundary separations that extended into the base metal. The weld shields were replaced for two (a LANL-return EU and a Qualification Production unit) of the 15 SCAs.

Only 3 of the 59 FQ SCAs made from the shield cups returned from LANL had to be downgraded to EU units. These were downgraded on NCR-CVS-020, Revision A because their minimum weld-shield-lengths-from-the-top-of-the-cups were too short. Two EUs, 3625-27-2375 and -2390, were retained at ORNL for a closure weld evaluation study (see section 2.C.4). Thus, $56 \mathrm{FQ}$ and 10 EU SCAs, were shipped to and received by LANL. J. S. Ivey, Quality Engineer from ORNL, and C. E. Grosso, Quality Engineer from Westinghouse Government Services Group, assisted LANL personnel in receipt inspection and re-matching the SCAs with their respective Vent Cup Assemblies (VCAs).

\subsubsection{Complete Qualification Production}

All 14 Qualification Production matched assemblies were re-matched after the Shield Cup Assembly (SCA) processing. Nine of the matched assemblies were FQ units and five were EU. The 9FQ and 2 of the EU Qualification Production matched assemblies were shipped to LANL. Three EUs were retained at the Oak Ridge National Laboratory (ORNL). Two of these, 9808-31-6009 (9753-30-A5NG/9754-31-A5P7) and 9808-31-6013 (9753-30-A5N8/9754-31-A5P8) will be part of a closure weld evaluation study. A third matched assembly, 9808-31-6010 (9753-30-4000/9754-02-A5NV) was used for a grain growth study.

\subsubsection{Produce 5 FQ CVS with Integral Weld Shield and Ship to LANL}

Twelve non-FQ blank assemblies were formed to evaluate two second-form dies (both with entrant radii of $0.300^{\prime \prime}$ and inside diameters of 1.2441" and 1.2448") and two second-form punches (nose lengths of $0.740^{\prime \prime}$ and $0.980^{\prime \prime}$ ). Three cups were formed for each of the four punch/die combinations. The cup inspection results did not show clear differences between combinations. There may have been a tendency for less wrinkling with the larger 1.2448" diameter die. Also, the combination of the 1.2448 " diameter die and the $0.980^{\prime \prime}$ punch nose length seemed to produce a more uniform cup contour. Thus, the tooling combination of the 1.2448 " diameter die and the punch with the $0.980^{\prime \prime}$ nose length will be used for second-forming the $15 \mathrm{FQ}$ first-formed cups.

Three deviation requests, DR-CVS-025, -026 , and -027 were submitted and approved. All three deviation requests change the insert number designations to -05- for FQ parts and to -31- for EU parts. All CVS hardware made at ORNL with the common vent notch size of $0.40 / 0.50 \mathrm{~mm}$ and the integral weld shield design configuration will utilize the $-05-/-$ 31 - insert numbers. DR-CVS-025 details a number of modifications to the cup manufacturing procedure, GPHS-XF$3624 / 25$, which is now revision $R$. One of the key changes was to revise the first- and second-form tooling drawings which were missing some features and dimensions. Now, second-forming of 15 flight quality cups can proceed. DRCVS-026 modifies cup inspection procedure, GPHS-C-3624/25 (now revision T), to require that the cup diameter (inspection step 4) be measured approximately $6 \mathrm{~mm}$ from the open end to ensure measurement consistency from cup to cup. DR-CVS-027 modifies vent cup assembly procedure, GPHS-G-9753 (now revision V), primarily to record the condition of the decontamination cover after an acceptable leak rate is achieved.

\subsubsection{Assess the Effect on Vent Notch Width on Clad Girth Weld on CVS with Notch Combinations B and C and Containing Integral Weld Shields}

Two EU SCAs (3625-27-2375 and -2390) from the units returned from LANL for vent notch widening and incorporation of the integral weld shields were retained at ORNL for a closure weld evaluation study. The mating vent cup assemblies, 9753-00-1957 and -1834, were shipped from LANL and received at ORNL for this study. A total of 8 pairs of cups have been inspected and are available for this study which is intended to show whether closure weld problems might be encountered with the integral weld shield design coupled with the 2 wider vent notch combinations. The welding equipment is being checked in preparation for beginning this study. 


\subsubsection{Miscellaneous}

Four non-FQ cups, TC-33, $-35,-36$, and -38 were processed for a grain growth (critical strain) study. These cups were dimensionally measured after the following operations: recrystallizing, sizing, grit blasting, deforming with the cupholding device during the final scribing operation, and re-sizing. Samples will be taken from the cups and exposed to different heat treatments to see if abnormal grain growth (related to critical strain levels imparted from the intentional deformation) occurs. Laboratory samples subjected to bending strains of $1.3 \%$ and higher followed by annealing for $100 \mathrm{~h}$ at $1500^{\circ} \mathrm{C}$ in a vacuum of $10^{-4} \mathrm{~Pa}$ have been found to exhibit anomalous grain growth.'

A total of 159 shipping sleeves have been fabricated, cleaned, and inspected. Nineteen of these shipping sleeves were submitted and accepted on nonconformance report NCR-CVS-022 for excessive depth on the vent cup assembly side. A total of 128 (or $81 \%$ ) sleeves were accepted for FQ use.

Quotes for 200 to 400 polyethylene CVS shipping sleeves are being solicited. Ten first article evaluation units will be made and evaluated prior to manufacture of the production quantity. The sleeves will be dimensionally inspected first in the as-machined condition then again after ultrasonic cleaning (room temperature in Micro detergent for 10 minutes). If the parts are not dimensionally correct after ultrasonic cleaning, then dimensional compensation will be required and an additional 10 evaluation sleeves will be made. Once a set of 10 acceptable evaluation units is made, manufacturing of the production quantity will begin.

\subsubsection{Reference}

1. C. G. McKamey, E. P. George, E. H. Lee, and J. L. Wright, "Strain Induced Grain Growth in DOP-26 Iridium," attachment to Letter No. 0326-14-01 from J. P. Moore to A. S. Mehner, March 26, 2001.

\subsection{IRIDIUM POWDER AND INVENTORY MANAGEMENT}

The purpose of this work is to manage an iridium inventory for all heat source contractors with emphasis on the significant quantities of iridium located at the Mound Plant, Los Alamos National Laboratory (LANL), and ORNL, and to maintain a no-change iridium inventory through an annual write-off of inventory and processing losses.

\subsubsection{Shipments of Iridium}

The shipment of 66 alloy shield cup assemblies departed from ORNL on January 10 and arrived at LANL on January 11. The security seals on the shipping containers were all intact upon arriving at LANL. These 66 shield cups were at ORNL for widening of the vent notches and welding in integral weld shields.

The shipment of eleven Qualification Production alloy shield cup assemblies departed from ORNL on February 5 and arrived at LANL on February 6. The security seals on the shipping containers were all intact on arrival.

Two vent cup assemblies shipped from LANL were received at ORNL in February. 


\subsubsection{Iridium Accountability Reviews}

The planning of the annual physical inventory of iridium at ORNL, as required by the U. S. Department of Energy, has been completed. The physical inventory will be conducted the week of April 23 through April 27. The iridium accountability review will be performed after the completion of the physical inventory.

\subsection{SHIELD CUP MODIFICATION}

The goal of this activity is to widen the vent notches and install integral weid shields (IWSs) in 59 FQ and 9 EU shield cups returned from LANL. Also, IWSs must be installed in the 14 Qualification Production shield cups and then the shield cup assemblies (SCA) must be re-matched with the VCA's.

\subsubsection{Establishing Capability for Installing IWS}

The CVS Cleaning Area in Building 2525 at ORNL was re-opened after it had been shutdown temporarily for approximately 3 weeks because of housekeeping and safety concerns. The three CVS manufacturing procedures (GPHS-Y-005, -006, and -007) that require the use of acids were revised (DR-CVS-024) to state more clearly the specific types of chemical protective clothing that are required. These procedure modifications along with additional job hazard evaluations were done as part of the resumption of operations in the CVS Cleaning Area.

Two additional copies of the weld shield tab-to-shield cup weld fixture were successfully fabricated. New springs ( $7 / 16$ " long) were put in all 3 fixtures to ensure full travel for the tab hold-down fingers so that the wield shield tabs will always be held against the inside of the cup wall during welding.

\subsubsection{Processing of LANL Returns and Qualification Production Assemblies}

Four EU and five FQ shield cups returned from LANL were completed as SCAs per the special instruction deviation request, SIDR-CVS-003. C. E. Grosso and M. O. Smith of Westinghouse Government Services Group performed a follow-up assessment of the ORNL weld shield and shield cup assembly production preparedness on August 17, 2000. They examined the completed $4 \mathrm{EU}$ and $5 \mathrm{FQ}$ SCAs and reviewed the manufacturing records, procedures, deviation requests, and equipment. The Westinghouse personnel recommended to the DOE Office of Space and Defense Power Systems that ORNL be given permission for weld shield and shield cup assembly production.

Shortly after the review and recommendation by Westinghouse personnel, the DOE Office of Space and Defense Power Systems granted permission for ORNL to begin production. A total of 123 FQI WSs (3620-01) were initiated. Thirty one of these were scrapped for a yield of $75 \%$. Twenty two were scrapped for weld burnback which must not exceed $0.64 \mathrm{~mm}$ at either end. As production proceeded and the welder gained experience, less burnback problems were encountered. Eight weld shields were scrapped for cracks in tab radii that appeared after forming. These cracks were most likely related to the soundness of the stamped edges which is tied to foil/tooling conditions.

Weld Shields have been welded into all 14 Qualification Production shield cups along with the 9 EU and 59 FQ shield cups returned from LANL. Rewelding must occur on 3 FQ shield cups because of minor cracking in some tab welds that extend slightly into the cup base metal. All SCAs must be processed through air burn-off, vacuum outgassing, weld inspection, and dimensional inspection prior to certification review. Once the certification review is complete, the shield cups from LANL will be ready for shipment. The Qualification Production SCAs were re-matched with their respective VCAs, and the CVS from Qualification Production were shipped to LANL. 


\section{BASE TECHNOLOGY PROGRAM AND TECHNICAL SUPPORT ACTIVITIES}

\subsection{TECHNICAL SUPPORT FOR ADVANCED RADIOISOTOPE POWER SYSTEM (ARPS) AMTEC CELL DEVELOPMENT}

\subsubsection{Introduction}

The ARPS Program is developing the AMTEC cell as a possible thermal-to-electric power converter for outer planetary space missions being considered by NASA. These cells are fabricated from refractory metal alloys and use sodium as a working fluid with beta alumina solid electrolyte. ORNL is providing technical support to the AMTEC development program by producing arc-melted Mo- $41 \%$ Re alloy ingots and processing them to various product forms, welding fabrication development with the electron beam (EB) welding process, ceramic insulator to refractory alloy brazing development, and tungsten-rhodium (W-Rh) electrode coating on beta-alumina. The AMTEC Cell Program has now been directed to develop a chimney design fabricated from the Mo- $41 \% \mathrm{Re}$ alloy and demonstrate its improved conversion efficiency towards the end of FY 2002.

\subsubsection{MOLYBDENUM-41\% RHENIUM ALLOY PRODUCTION}

\subsubsection{Shipments of Plate, Rod, and Wire Products}

All shipments of Mo-41 Re alloy requested by AMPS for two developmental cells have been completed. The shipments were as follows:

\begin{tabular}{|c|c|c|c|c|}
\hline ITEM & DIMENSIONS & QTY & DATE & 1.D. \\
\hline $\begin{array}{l}\text { blanks } \\
\text { blanks } \\
\text { blanks }\end{array}$ & $\begin{array}{l}0.020 \pm 0.002 " \text { thick } 3.00 \pm 0.020^{\prime \prime} \text { dia. } \\
0.040 \pm 0.002^{\prime \prime} \text { thick } 5.00 \pm 0.020^{\prime \prime} \text { dia. } \\
0.040 \pm 0.002^{\prime \prime} \text { thick } 3.50 \pm 0.020 " \text { dia. }\end{array}$ & $\begin{array}{l}12 \\
12 \\
12\end{array}$ & $\begin{array}{l}12 / 13 / 00 \\
01 / 17 / 01 \\
01 / 08 / 01\end{array}$ & $\begin{array}{l}\text { MR1-3 } \\
\text { MR3-2, -3, -4 } \\
\text { MR3-1, -5 }\end{array}$ \\
\hline $\begin{array}{l}\text { plate } \\
\text { plate } \\
\text { plate }\end{array}$ & $\begin{array}{lrl}0.080^{\prime \prime} & \text { thickness } & 2.5^{\prime \prime} \text { square } \\
0.50^{\prime \prime} & \text { thickness } & 2.5 " \text { square } \\
0.50^{\prime \prime} & \text { thickness } & 2.5^{\prime \prime} \text { square }\end{array}$ & $\begin{array}{l}4 \\
2 \\
2\end{array}$ & $\begin{array}{l}01 / 04 / 01 \\
01 / 31 / 01 \\
02 / 12 / 01\end{array}$ & $\begin{array}{l}\text { MR3-11 } \\
\text { MR5-10 } \\
\text { MR5-9 }\end{array}$ \\
\hline $\begin{array}{l}\text { rod } \\
\text { rod } \\
\text { rod }\end{array}$ & $\begin{array}{l}0.1875^{\prime \prime} \text { diameter } 24 \text { " total length } \\
0.500^{\prime \prime} \text { diameter } 24^{\prime \prime} \text { total length } \\
0.875^{\prime \prime} \text { diameter } 0.5^{\prime \prime} \text { length }\end{array}$ & 6 & $\begin{array}{l}01 / 16 / 01 \\
01 / 29 / 01 \\
01 / 04 / 01\end{array}$ & $\begin{array}{l}\text { MR2-4 } \\
\text { MR4-1 } \\
\text { MR3-9 }\end{array}$ \\
\hline wire & $0.062^{\prime \prime}$ diameter $57^{\prime \prime}$ length & 4 & $02 / 13 / 01$ & MR2-4 \\
\hline
\end{tabular}

\subsubsection{Production of Blanks for Forming}

Blanks for the upper cell wall were produced from bar section MR1-3. The extruded bar section of 0.75 by 2.0 by $5^{\prime \prime}$ length was machined to 0.61 by $1.8^{\prime \prime}$ to remove surface defects. The bar was recrystallized at $1500^{\circ} \mathrm{C}$ for 1 hour in vacuum. The bar was covered with a molybdenum sheet, heated to $1200^{\circ} \mathrm{C}$ for $10 \mathrm{~min}$ and cross rolled to $2.6^{\prime \prime}$ width with roll reductions of $15 \%$ per pass. The sheet was then recovered and preheated to $1000^{\circ} \mathrm{C}$ and rolled in the extrusion direction to 0.25 " thickness. The sheet was cleaned in an acid solution of $21 \%$ nitric, $52 \%$ phosphoric, $6 \%$ hydrofluoric, and $21 \%$ acctic, with all amounts as concentrated volume $\%$. Immersion times were about 60 seconds. The sheet was again recrystallized at $1500^{\circ} \mathrm{C}$ and then covered and hot rolled to $0.125^{\prime \prime}$ thickness as described above. The sheet was cut to 4 " lengths which were covered, preheated to $700^{\circ} \mathrm{C}$ for 30 minutes and cross rolled to $3.5^{\prime \prime}$ width. The sheets were cleaned in acid and recrystallized in vacuum for 1 hour at $1400^{\circ} \mathrm{C}$. The sheets were preheated to $400^{\circ} \mathrm{C}$ for 15 minutes and rolled without covers on the 4 -high mill with carbide rolls to a thickness of $0.020^{\prime \prime}$. The sheets received intermediate recrystallization anneals of 1 hour at $1400^{\circ} \mathrm{C}$ at gauge thicknesses of 0.085 and $0.040^{\prime \prime}$. Samples of the 
sheet were heated for 1 hour at temperatures from $800^{\circ}$ to $1300^{\circ} \mathrm{C}$. Metallography of these samples showed full recrystallization at $1200^{\circ} \mathrm{C}$ and no visible indication of recrystallization at $1100^{\circ} \mathrm{C}$. The sheets were cleaned and stress relieved at $1000^{\circ} \mathrm{C}$ for 60 minutes in a vacuum. Blanks of $3.00^{\prime \prime}$ diameter were prepared by electro-discharge machining (EDM) using molybdenum wire with deionized water as lubricant. The blanks were cleaned and stress relieved at $1000^{\circ}$ $\mathrm{C}$ for 60 minutes in a vacuum. The blanks were shipped to AMPS on December 14,2000. Two of the twelve blanks had surface damage from improper machining practice within 0.12 " from the edge and one blank showed a hole extending to 0.12 " from the edge.

Blanks for the lower cell wall and transition section were produced from extruded sections MR3-2, -3 , and -4 . Blanks for cold end component were produced from extruded sections MR3-1, and -5 . The extruded sections were machined to approximately 0.6 by $1.8^{\prime \prime}$ to remove surface defects and molybdenum can material. The bars were placed in molybdenum covers, preheated to $700^{\circ} \mathrm{C}$ and cross-rolled to obtain a thickness of $0.35^{\prime \prime}$ in a similar manner as described above for the MR 1-3 materials. The bars were then cleaned and recrystallized at $1500^{\circ} \mathrm{C}$. The bars were again covered and cross rolled to obtain a width of 4 " for sections MR3-1, and -5 , or a width of 5.5" for sections MR3-2, -3 , and -4 . Small surface defects were removed by light manual grinding prior to each cleaning step. The sheets were then rolled in the extrusion direction with molybdenum covers as described above with an intermediate anneal at $1500^{\circ} \mathrm{C}$ at a gauge thicknesses of 0.20 and $0.12^{\prime \prime}$. The sheets were preheated to $400^{\circ} \mathrm{C}$ for 15 minutes and rolled without covers on the 4-high mill with carbide rolls to a thickness of $0.040^{\prime \prime}$, with an intermediate recrystallization anneal of 1 hour at $1400^{\circ}$ $\mathrm{C}$ at a gauge thickness of $0.070^{\prime \prime}$. The sheets were cleaned and stress relieved at $1000^{\circ} \mathrm{C}$ for 60 minutes in a vacuum. Blanks of a both $3.50^{\prime \prime}$ and $5.00^{\prime \prime}$ diameter were prepared by electro-discharge machining.

\subsubsection{Production of Other Plate Products}

The extruded section MR3-11 was initially processed to plate of 0.14 " thickness. This material was later returned from AMPS for reworking to produce a 0.08 " thick sheet. The MR3 extruded sheet bar of $0.75 \times 2.0$ inch cross section was cut to produce a $4.5^{\prime \prime}$ length identified as MR3-11. The material was heated at $1500^{\circ} \mathrm{C}$ in vacuum for 1 hour and warm rolled at $700^{\circ} \mathrm{C}$ in the direction normal to the extrusion to 0.55 -inch thickness. (Also a metallographic examination of the plate at 0.55 -inch thickness showed many regions of large elongated grains in the original extrusion indicative of a need for greater than $20 \%$ reduction prior to the final anneal.) The material was recrystallized at $1500^{\circ} \mathrm{C}$. The plate was further warm rolled at $700^{\circ} \mathrm{C}$ preheat to 0.27 inch thickness, ground to 0.24 inch thickness to remove surface defects and again recrystallized at $1500^{\circ} \mathrm{C}$. The plate was rolled to a thickness of 0.125 to 0.145 inch, cleaned and recrystallized. Metallographic analysis shows a gain size of about $25 \mu \mathrm{m}$. After return of the plate from AMPS on March 14,2001, the plate was cleaned with alcohol, preheated to $400^{\circ} \mathrm{C}$ and rolled on the 4-high mill to a final thickness of 0.080 " in multiple passes of about $10 \%$ each using 5 minute reheats. The sheet was flattened with the Mesta mill. The sheet was then cleaned, recrystallized at $1400^{\circ} \mathrm{C}$ and returned to AMPS.

Plate of $0.48^{\prime \prime}$ thickness was produced from extruded bar MR5 with a 1 by 2 " cross section. Two sections of 6 " length labeled as MR5-9 and - 10 were placed in molybdenum covers and cross rolled to 0.63 " thickness with a preheat of 30 minutes at $700^{\circ} \mathrm{C}$ ( 15 minute reheats) and approximate $10 \%$ roll reduction per pass. Acid pickeling resulted in nonuniform removal of the molybdenum cover. The plates were flattened with a $700^{\circ} \mathrm{C}$ preheat and machined to $2.5^{\prime \prime}$ square by $0.48^{\prime \prime}$ thick. The machined plates were cleaned and recrystallized at $1400^{\circ} \mathrm{C}$.

The $0.875^{\prime \prime}$ diameter material was produced from one section of extruded bar labeled MR3-9 which was hot forged at $1200^{\circ} \mathrm{C}$ from $0.75^{\prime \prime}$ thickness by $2^{\prime \prime}$ width to $1.00^{\prime \prime}$ thickness by $1.25^{\prime \prime}$ width. The bar was recrystallized and then cross rolled to plate of $0.55^{\prime \prime}$ thickness. Metallographic analysis of a sample recrystallized at $1500^{\circ} \mathrm{C}$ indicated a grain size of 50 to $100 \mu \mathrm{m}$, with evidence of prior grain boundaries from extrusion visible in some regions of the microstructure. The microstructure was deemed satisfactory for the intended use. (There was no way to produce a fully uniform recrystallized structure with this relatively large bar diameter in a timely fashion.) Six pieces, each of about 0.50 " length were machined. 


\subsubsection{Production of Wire}

The wire was produced starting with a rod of $0.62^{\prime \prime}$ diam machined from MR2-4 sheet bar. The rod was warm swaged with a preheat temperature of $700^{\circ} \mathrm{C}$ to $0.22^{\prime \prime}$ diameter with intermediate vacuum anneals of $1400^{\circ} \mathrm{C}$ for 1 hour at 0.45 and $0.30^{\prime \prime}$ diameter. The rod was then centerless ground to $0.18^{\prime \prime}$ diameter and again recrystallized. This rod was warm drawn to wire using tooling preheated to $400^{\circ} \mathrm{C}$ with an aqueous dispersion of molybdenum disulfide as a lubricant. The wire was acid cleaned prior to in-process vacuum anneals of $1400^{\circ} \mathrm{C}$ for 1 hour at $0.12^{\prime \prime}$ and $0.085^{\prime \prime}$ diameter. The wire was coiled for the final anneal at $1400^{\circ} \mathrm{C}$ and then straightened by tensioning. The wire was shipped as four lengths of 57" each on February 13. The wire showed a good surface finish and dimensional tolerance of $0.0619 \pm$ $0.0002 "$.

\subsubsection{Production of Rod}

Rod of $0.5^{\prime \prime}$ diameter was produced from the 1.5" diameter MR4 extrusion. A length of 10" labeled MR4-1 was preheated for 1 hour at $700^{\circ} \mathrm{C}$ and swaged to $1.22^{\prime \prime}$ diameter with 15 minute reheats and straightened. The bar was machined to $1.06^{\prime \prime}$ diameter to remove the molybdenum can material and surface flaws. The bar was then swaged to $0.875^{\prime \prime}$ diameter using 30 minute preheat and 15 reheats at $700^{\circ} \mathrm{C}$. The material was cleaned and recrystallized at $1400^{\circ} \mathrm{C}$. The bar was then swaged to $0.65^{\prime \prime}$ diameter using 30 minute preheat and 15 reheats at $700^{\circ} \mathrm{C}$. The material was cleaned and recrystallized at $1400^{\circ} \mathrm{C}$.

Rod material was produced from $0.63 "$ diameter sections machined from extrusion section MR2-4. The material was recrystallized at $1400^{\circ} \mathrm{C}$ and then was warm swaged to $0.22^{\prime \prime}$ diameter with intermediate recrystallization anneals at 0.45 and $0.30^{\prime \prime}$ diameter. The rod was acid cleaned, and recrystallized at $1400^{\circ} \mathrm{C}$ for 1 hour.

\subsubsection{Chemical Analysis of Mo-Re Alloy Products}

The results of chemical analyses of the Mo-41\%Re alloy materials provided to AMPS are listed in Table 1 below. The rhenium contents measured by atomic absorption by Shiva Technologies, Inc. (Syracuse, NY) are all in the range of 40.7 to $41.6 \mathrm{wt}$. \%. The carbon and oxygen contents measured by CSM (Coldwater, MI) are all consistently in the range of 98 to $110 \mathrm{ppm}$ carbon and 3 to $15 \mathrm{ppm}$ oxygen, with the exception of the MR1-3 material. This material, for $0.020^{\prime \prime}$ thick disks for forming, has a significantly lower carbon content of $20 \mathrm{ppm}$. The analysis of all impurities other than oxygen was performed by glow discharge mass spectrometry (GDMS). The impurity levels are generally consistent with an electron-beam melted product. All show a residual tungsten content of about $60 \mathrm{ppm}$, and some low levels of niobium and iridium. The MR2-4 material used for wire production shows a somewhat higher level of iron and chromium than the other materials. 
Table 1. Chemical Composition of Molybdenum-41\% Rhenium Alloy Products

\begin{tabular}{|l|c|c|c|c|c|c|c|}
\hline \multicolumn{7}{|c|}{ Concentration, ppm by weight except for Re which is in weight \% } \\
\hline Element & MR1-3 & MR2-4 & MR3-3 & MR3-9 & MR3-11 & MR4-1 & MR5-10 \\
\hline \hline $\mathrm{B}$ & 0.12 & 0.04 & 0.08 & 0.03 & 0.21 & 0.11 & 0.02 \\
$\mathrm{C}$ (Leco) & 20.3 & 103 & 99 & 101 & 98 & 104 & 10 \\
$\mathrm{O}$ (Leco) & 8.6 & 14.9 & 7.7 & 3.7 & 7.8 & 7.1 & 7.1 \\
$\mathrm{Al}$ & 0.03 & 1.1 & 0.28 & 0.12 & 0.06 & 0.02 & 0.01 \\
$\mathrm{Si}$ & 1.7 & 1.2 & 0.1 & 0.31 & 0.25 & 0.04 & 0.05 \\
$\mathrm{P}$ & 0.02 & 0.02 & 0.03 & $<0.01$ & 0.01 & $<0.01$ & $<0.01$ \\
$\mathrm{Cl}$ & 0.04 & 0.04 & 0.04 & $<0.01$ & $<0.01$ & $<0.01$ & $<0.01$ \\
$\mathrm{Ca}$ & $<0.05$ & $<0.05$ & $<0.05$ & $<0.05$ & $<0.05$ & $<0.05$ & $<0.05$ \\
$\mathrm{~V}$ & 0.03 & 0.55 & 0.06 & 0.08 & 0.11 & 0.22 & 0.07 \\
$\mathrm{Cr}$ & 0.33 & 5.4 & 0.16 & 0.29 & 0.34 & 1.8 & 0.41 \\
$\mathrm{Fe}$ & 0.66 & 45 & 1.2 & 1.9 & 2.7 & 15 & 3 \\
$\mathrm{Co}$ & 0.01 & 0.02 & 0.01 & 0.02 & 0.02 & 0.02 & 0.01 \\
$\mathrm{Ni}$ & 0.15 & 0.76 & 0.07 & 0.12 & 0.17 & 0.17 & 0.05 \\
$\mathrm{Cu}$ & 7.9 & 0.05 & $<0.05$ & $<0.05$ & $<0.05$ & $<0.05$ & $<0.05$ \\
$\mathrm{Zr}$ & 0.11 & 0.59 & 0.27 & 0.2 & 0.19 & 0.06 & 0.11 \\
$\mathrm{Nb}$ & 0.74 & 0.97 & 1.9 & 2 & 2.4 & 8.3 & 1.1 \\
$\mathrm{Hr}$ & $<0.01$ & 0.01 & $<0.01$ & $<0.01$ & $<0.01$ & $<0.01$ & 0.08 \\
$\mathrm{~W}$ & 60 & 59 & 57 & 58 & 56 & 57 & 55 \\
$\mathrm{Re}(\%)$ & 40.7 & 40.8 & 41.6 & 41.5 & 41.5 & 41.3 & 41.3 \\
$\mathrm{Ir}$ & 3.1 & 2 & 1 & 1.4 & 1.1 & 17 & 13 \\
$\mathrm{Th}$ & $<0.005$ & 0.009 & $<0.005$ & $<0.005$ & $<0.005$ & $<0.005$ & $<0.005$ \\
$\mathrm{U}$ & $<0.01$ & 0.017 & $<0.01$ & $<0.01$ & 0.005 & $<0.005$ & $<0.005$ \\
\hline
\end{tabular}

There is no specification for the chemical composition of the material. In evaluating the results of the chemical analysis comparisons can be made to the specification for arc-melted commercially pure molybdenum, ASTM B387. Impurity levels in Mo-Re alloys are discussed by Lynn Lundberg (Solid Solution Molybdenum-Rhenium Alloys in Rhenium and Rhenium Alloys, ed. Boris Bryskin, TMS, Warrendale, PA, 1997, p.374) who gives typical impurity levels for "quality" products. The impurity contents listed in these two documents are shown in Table 2 (with the recommendations of Lundberg converted from atom \% basis.)

Table 2. Published Chemical Composition Limits for Molybdenum and Mo-Re Alloys

\begin{tabular}{|c|c|l|}
\hline \multicolumn{2}{|c|}{ Maximum Impurity Content, wt. ppm } \\
\hline Element & ASTM B 387 & \multicolumn{1}{c|}{ Lundberg (1997) } \\
\hline $\mathrm{C}$ & 300 & 100 (and minimum 2.7 times O content) \\
$\mathrm{O}$ & 15 & 25 \\
$\mathrm{Fe}$ & 100 & 50 \\
$\mathrm{Ni}$ & 20 & \\
$\mathrm{Si}$ & 100 & 50 \\
$\mathrm{Ca}$ & & 15 \\
\hline
\end{tabular}

All of the materials meet the chemical requirements of specification ASTM B 387 (except for rhenium). All of the materials also are consistent with the recommendations of Lundberg, with the exception that the carbon contents range 
up to $110 \mathrm{ppm}$ rather than $100 \mathrm{ppm}$. Also the MRl-3 material has a carbon to an oxygen ratio of 2.4 as compared to the 2.7 minimum recommended by Lundberg

In summary all of the materials are expected to be fit for use. The MRI-3 material is near the low end of the acceptable carbon content. All other materials are likely near the high end of the acceptable carbon content.

\subsubsection{Arc Melting and Extrusion}

The MR5 and MR6 ingots were vacuum arc remelted using the same methods as for previous melts with the exception that the steady state control voltage was increased from $36.5 \mathrm{~V}$ to $37 \mathrm{~V}$. This increased the arc gap slightly and reduced current and voltage fluctuations during the melt.

The MR4 ingot was sealed in an evacuated molybdenum can and preheated in argon gas by induction heating to a can temperature of $1850^{\circ} \mathrm{C}$ as measured by a two color optical pyrometer. The canned ingot was extruded through a zirconia-coated die of $1.5^{\prime \prime}$ diameter opening with a maximum press load of 725 tons. The MR5 ingot was prepared similarly and extruded through a rectangular die opening of 1 by 2 " with a maximum press load of 650 tons. (Press capacity for 3.5 inch tooling is 940 tons)

The material remaining available for future processing consists of an extruded MR5 sheet bar of $1 \times 2 \times 14^{\prime \prime}$, extruded MR4 round bar of 1.5 " diam by 17 " length, and the unextruded MR6 ingot.

\subsubsection{AMTEC Cell Fabrication Development}

Fabrication support for the AMTEC cell development at AMPS was continued for the remaining Nb-1Zr cells, and work was initiated toward fabrication of the chimney cell during this reporting period. Frequent communications were made on various aspects of the cell wall fabrication trials which are underway. Weld joint dimensional tolerances were discussed and specified for some joints of the chimney cell design.

ORNL assembled and joined by electron beam welding three top cap/pumpout port assemblies during this reporting period. AMPS prepared the Nb- IZr components in Matched Kits numbered E99-0213, E99-0214, and E99-0250. The ivelds were made to established procedures for these components. Visual examination of the weldments indicated all three were satisfactory. Each assembly was packaged, sealed in an argon gas-purged bag, and returned to AMPS.

Welding fabrication of the EPX-01-E6 cell was completed. This is a $\mathrm{Nb}-\mathrm{IZr}$ cell which will test the latest artery/evaporator design and has improved mechanical seals of Beta tube assemblies. The cell components were assembled at ORNL by an AMPS technician. The assembly and electron beam (EB) welding of the cell proceeded without incident and was performed to established procedures. All welds had good visual appearance with no apparent discontinuities. Final helium leak testing revealed a large leak in the containment of the cell. The cell was returned to AMPS where additional leak testing and visual inspection was performed. A defect/inclusion was discovered in the base material of one of the caps in the hot end BASE support plate. This was repaired by EB welding over the area at AMPS. An additional small leak area in the cell wall is being examined at AMPS. Repair options are being evaluated.

Welding development tests are underway for joining the BASE tube flanges to the Mo-41\%Re BASE support plates. A transition material was needed to permit welding the $\mathrm{Nb}-1 \mathrm{Zr}$ support tube assembly to the Mo- $41 \%$ Re BASE support plate. Previous work had shown that cracking was prevalent in welds between Mo-4l\%Re and $\mathrm{Nb}-1 \mathrm{Zr}$. A pure molybdenum ring was EB welded to the Nb-1Zr component at AMPS. This Mo section of the support tube assembly was then welded to the Mo- $41 \%$ Re support plate. Two test weldments have been produced with the EB process using the techniques previously developed for the Nb-1Zr AMTEC cells. Welding parameters are being adjusted to produce a weld with uniform appearance and adequate penetration. Both welds appear to be satisfactory for this joint. No evidence of cracking or other weld defects has been detected. Additional metallographic specimens are being prepared for examination. 


\subsubsection{Brazing Development for AMTEC Cells}

Braze Joint Analysis - Preparations were made to analyze the effects of materials properties and brazing temperature on the residual stress distributions in joints of either aluminum oxide $\left(\mathrm{Al}_{2} \mathrm{O}_{3}\right)$ or aluminum nitride (AIN) with either niobium ( $\mathrm{Nb}$ ) alloys or molybdenum (Mo) alloys. An axisymmetric model representing a cylindrical geometry will be used to simplify the analysis and to illustrate the major effects, Fig. 1. Residual stresses will increase with increases in either the mismatch of coefficients of thermal expansion (CTE) or brazing temperature. This modeling activity is not meant for predicting joint failure. Rather, the analysis will be used to provide a rational way to optimize the design of feedthrough configurations and brazing temperatures. Material property input files for the materials in question were also compiled.

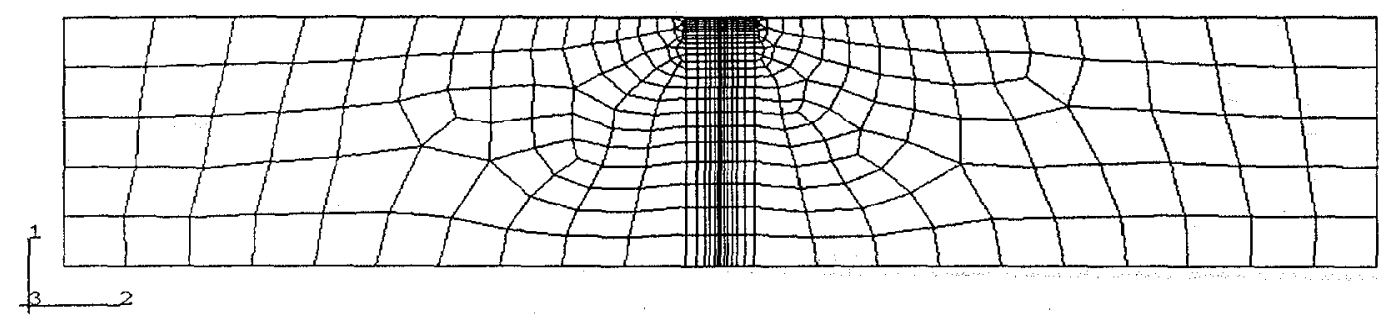

Fig. 1. Geometric model being used to analyze residual stresses in braze joints. Only half of the joint is shown because the model is axisymmetric about the 2-3 axis. The braze joint is the dark vertical line at the center of the model. The upper edge of the model represents the outer surface of the cylindrical joint.

Brazing Trials, $\mathrm{Al}_{2} \mathrm{O}_{3}$ Joints - Several trials were made to braze $\mathrm{Al}_{2} \mathrm{O}_{3}$ to $\mathrm{Nb}$ tubing using pure vanadium $(\mathrm{V})$ foil as a filler metal. The trials were conducted to help establish processing conditions that could be used to fabricate a test AMPS feedthrough at ORNL. The brazing trials were done by induction heating in a vacuum chamber as shown in Fig. 2. Vacuum levels were in the range of $2 \times 10^{-6}$ torr prior to heating of the specimens, and drifted to the low $10^{-4}$ torr range during heating. Temperature was monitored with an optical pyrometer that was calibrated at the melting point of pure nickel $\left(1453^{\circ} \mathrm{C}\right)$. The pyrometer indicated that temperatures in excess of $2000^{\circ} \mathrm{C}$ were achieved in the $\mathrm{Nb}$ tubing during the trials. However, complete melting of the $V$ foil $\left(T_{M}=1900^{\circ} \mathrm{C}\right)$ did not occur.

Because of the difficulties experienced with melting vanadium foil in mock feedthrough joints, it was decided to attempt melting of $\mathrm{V}$ from another source. A small pellet of commercially pure $\mathrm{V}$ was cut from rod stock and set up for induction melting in the system previously described. The $\mathrm{V}$ pellet was approximately cubic in shape with $3 \mathrm{~mm}$ long sides. It was positioned on a piece of $6 \times 6 \times 1 \mathrm{~mm} \mathrm{Al} \mathrm{O}_{3}$. The $\mathrm{Al}_{2} \mathrm{O}_{3}$ was positioned on a $6 \mathrm{~mm}$ cube of tantalum to assist coupling with the magnetic field of the induction coil. Initial attempts to melt the $\mathrm{V}$ pellet failed and pyrometer readings confirmed that the melting point of $V$ was not being reached. An induction coil of smaller ID (19 mm vs. 25 $\mathrm{mm}$ ) was then made and the experiment was repeated. Heating with the smaller coil produccd melting of the $V$, and pyrometer readings in the range of $1900^{\circ} \mathrm{C}$ were observed. This experiment confirmed that the melting temperature of $\checkmark$ could be achieved in our induction system on parts that were similar in size to the feedthrough. An additional attempt to melt a piece of $V$ foil using the same set-up was unsuccessful. We believe that a possible reason for the problems experienced with melting $\mathrm{V}$ foil relate to the difficulty of magnetic field coupling to thin parts. 


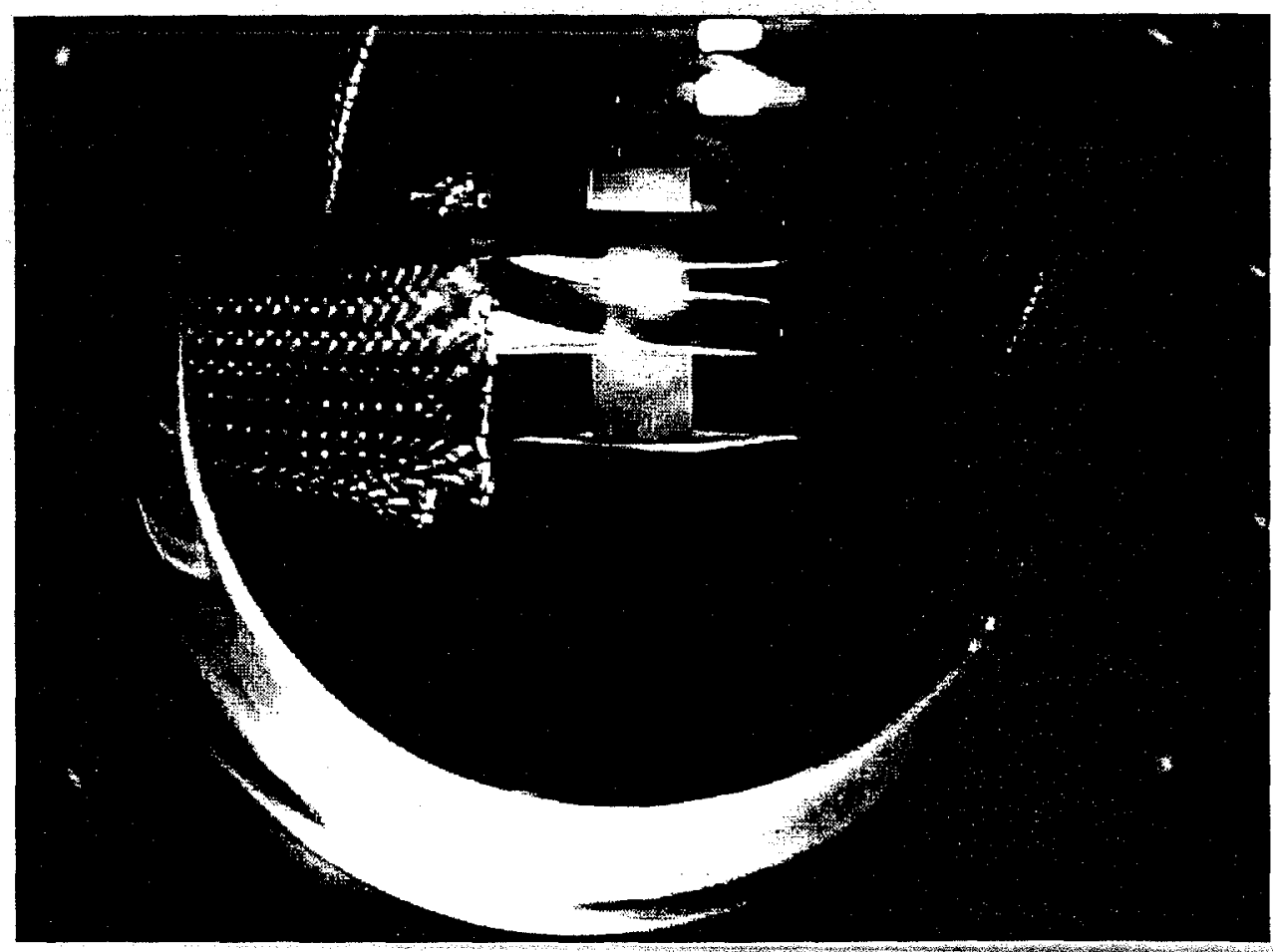

Fig. 2. Induction brazing trial during heating as viewed through a window in the vacuum chamber. The assembly consisted of $\mathrm{Al}_{2} \mathrm{O}_{3}$ between two pieces of $0.25 " \mathrm{Nb}$ tubing with $\mathrm{V}$ foil and the appropriate interfaces. $\mathrm{A}$ small $\mathrm{Al}_{2} \mathrm{O}_{3}$ spacer and a tungsten weight capped the assembly.

Several joints were made of $\mathrm{Al}_{2} \mathrm{O}_{3}$ to either pure Mo, Mo-rhenium ( $\mathrm{Re}$ ), or pure $\mathrm{Nb}$ by vacuum furnace brazing with a filler metal of nominal composition $48 \mathrm{Ti}-48 \mathrm{Zr}-4 \mathrm{Be}$ where the numbers indicate wt $\%$. The brazing temperature used was $1050^{\circ} \mathrm{C}$. Visual examination of the joints showed that wetting and overall appearance was good. The results of initial metallographic examination of the Mo-Re joint are shown in Fig. 3. The unetched specimen shows that the joint contained a small amount of porosity, but no cracks were observed in the filler metal or the $\mathrm{Al}_{2} \mathrm{O}_{3}$. The etched specimen shows that a relatively thick layer formed at the $\mathrm{Al}_{2} \mathrm{O}_{3}$ joint surface, but chemical reaction with the $\mathrm{Al}_{2} \mathrm{O}_{3}$ appeared to be limited. We believe the high $\mathrm{Ti}+\mathrm{Zr}$ content of this braze filler metal coupled with its relatively low melting characteristics warrants its further evaluation for the feedthrough application.

Brazing Trials, AIN Joints - Based on guidance from AMPS a small quantity of aluminum nitride (AIN) was acquired, and an evaluation of its brazing characteristics was initiated. Because the TiZrBe filler metal alloy appeared to behave so well with the Mo-41\%Re to $\mathrm{Al}_{2} \mathrm{O}_{3}$ joints', it was used for the initial work on the AlN. A specimen of TiZrBe was melted on the AIN by induction to check its melting and wetting characteristics. The braze alloy melted during heating to about $1350^{\circ} \mathrm{C}$, and it formed a uniform droplet on the AlN with a wetting angle below $20^{\circ}$. However, the droplet did not adhere to the AIN after it was cooled to ambient temperature. An attempt to braze $\mathrm{Mo}-41 \% \mathrm{Re}$ to $\mathrm{Al}_{2} \mathrm{O}_{3}$ with the $\mathrm{TiZrBe}$ was also unsuccessful for the same reason. An alloy of $64 \mathrm{Ti}-32 \mathrm{~V}-4 \mathrm{Be}$, wt $\%$ was prepared and also evaluated on the AIN with similar results. Preparations are being made to make braze joints using $\mathrm{V}$ foil as a filler metal as well as several additional alloys.

AIso, efforts are continuing to identify alternative braze filler metals that might be compatible with the AMPS service requirements but that melt at temperatures significant lower than that of pure $V$. 

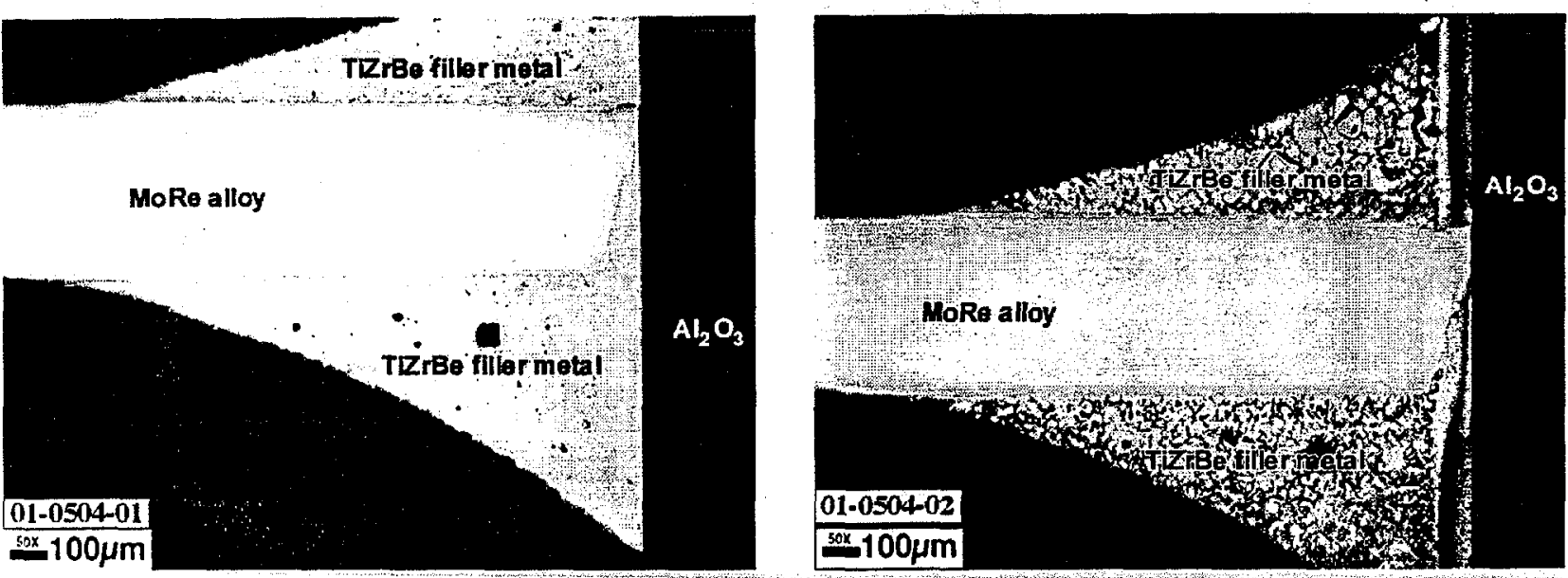

Fig. 3. T-joint of Mo-Re vacuum furnace brazed to $\mathrm{Al}_{2} \mathrm{O}_{3}$ with $\mathrm{TiZrBe}$ filler metal. Unetched view is shown on left; etched view is shown on right.

\subsubsection{Tungsten-Rhodium Electrode Coating}

Most of the activities during this early stage have been focused on bringing the equipment back to standard operating conditions following an extended period of time in stand-down mode.

The vacuum system was fully examined to determine that it would operate in the nominal specification range which is near $1 \times 10^{-6}$ torr. The vacuum system evaluation identified an electrical problem which was repaired so that an essential vacuum valve could be properly opened and closed. In addition, it was noted that the main cryo pump was operating in an off-normal manner. It was decided that the pump should be regenerated to determine if this would correct the problem, but it did not. It was also determined that the cryo pump was going to fail when it began to operate at an elevated temperature. A replacement component for the pump was located, installed, and regenerated. The base vacuum level of $1 \times 10^{-6}$ torr was again established and the cyro pump operates at normal temperatures.

During the stand-down period the motor used for rotating the fixture was lost to another program. A new motor was purchased and was installed. The fixture that had previously been used was in disrepair and needed to be overhauled. Additionally, the dimensions of the beta alumina tubes to be coated had changed from bare tubes to beta tube assemblies which required changing the fixture. The necessary repairs and design modifications have been made and the fixture was reassembled and tested.

Four magnetrons were reassembled and tested. Three of the four were working properly and will provide adequate capability for tandem coating with a back up. Two of the magnetrons were put into place, aligned with the tube fixture and tested. The program stand-down period caused a longer-than-expected start up of the coating system, but it is now operating correctly and has been used for a preliminary $\mathrm{W} / \mathrm{Rh}$ coating on a beta alumina test tube.

\subsection{ALLOY DEVELOPMENT AND CHARACTERIZATION}

\subsubsection{Oxygen Compatibility of Ce-Doped Iridium Alloys at $1330{ }^{\circ} \mathrm{C}$ in an Oxygen Partial Pressure of $1.3 \mathrm{mPa}$}

The iridium alloy designated as DOP-26 was developed at Oak Ridge National Laboratory for cladding plutonium oxide fuel pellets in radioisotope thermoelectric generators (RTGs). Its nominal composition is $\mathrm{Ir}-0.3 \mathrm{wt} \% \mathrm{~W}$ and it contains $60 \mathrm{ppm} \mathrm{Th}$. The addition of trace levels $\left(30-100 \mathrm{ppm}^{\dagger}\right)$ of thorium to $\mathrm{Ir}+0.3 \% \mathrm{~W}$ has been shown to greatly improve the high temperature impact ductility [1]. Auger electron spectroscopy has indicated that thorium segregates strongly to the grain boundaries in this alloy [2], resulting in increased cohesive strength of the boundaries and a change in fracture mode from intergranular fracture (in the undoped alloy) to ductile transgranular fracture (in the thorium-doped alloy). In addition to segregating to grain boundaries, thorium in excess of the solubility limit forms a second phase with 
a composition of $\operatorname{Ir}_{5} T h[3]$, which pins the grain boundaries and results in grain size refinement. Together these two factors contribute to an improvement in the high-temperature high-strain-rate tensile impact ductility [1].

Although the addition of thorium improves the impact ductility, it is very detrimental to the weldability [4]. The $60 \mathrm{ppm}$ level of Th in DOP-26 was chosen to give a good balance of these two properties. Since Th is also a radioactive element, there are several potential problems in using this element as an alloying addition. Refining of the element is expensive, and if the scrap cannot be refined commercially the cost of recovery will continue to increase. Additionally, the increasingly strict environmental, safety, and health regulations may make it more costly to work with DOP-26 in the future. Currently, the $60 \pm 30 \mathrm{ppm}$ specification for thorium in DOP-26 is just under the limit at which this alloy would be designated as radioactive. If these limits were to become stricter in the future, DOP- 26 would have to be handled as a radioactive material and its manufacturing and handling costs would dramatically increase. From these standpoints it is prudent to search now for a suitable alternative alloying element to replace Th in DOP-26, so that backup alloys will be available when needed.

Considerable progress has been made in our alloy design effort to develop an alloy with a lower thorium addition than that currently used in DOP-26. In 1995, an alloy containing $29 \mathrm{ppm} \mathrm{Ce}$ and $18 \mathrm{ppm}$ Th was chosen for scale up and was designated as DOP-Ce or DOP-40 [5]. Compared to DOP-26, this alloy has been shown to have better weldability, comparable impact ductility, and comparable grain growth in vacuum [6-9]. Because it is also desirable to know the grain growth characteristics of this alloy in low pressures of oxygen, as soon as specimens were available, they were included in our oxygen compatibility tests.

Over the past seven years, low-pressure oxygen compatibility tests have been conducted on several DOP-26 iridium alloys from both the old and new fabrication processes [10-16]. The conditions of each test, the alloys included in each test, and the dates of the final reports are shown in Table I. The old-process ZR and new-process D2 materials were tested at 1230,1280 , and $1330^{\circ} \mathrm{C}$ in oxygen partial pressures of both 1.3 and $13.3 \mathrm{mPa}$. The results of those tests indicate that there is no significant difference in grain growth behavior between the old- and new-process DOP-26 alloys. Various Ce-doped alloys have also been included over the years as the development of the Ce-doped alloy has progressed. Specimens of DOP-40 (I1 ingot) have been included in the three series of tests at the $13.3 \mathrm{mPa}$ oxygen level [13-15]. Earlier tests at an oxygen level of $1.3 \mathrm{mPa}$ [10-12] have included various Ce-doped experimental alloys whose compositions are shown in Table I. Recent impact test results indicate that DOP-40 alloys containing $20-40 \mathrm{ppm} \mathrm{Ce}$ and $30-50 \mathrm{ppm}$ Th have as good or better impact ductilities than currently used DOP-26 iridium over the entire temperature range tested $\left(800-1300^{\circ} \mathrm{C}\right)[9,17]$. Therefore, information on the oxygen compatibility of these particular alloys is needed. These tests are needed in order to determine whether cerium, which has been found to segregate to grain boundaries and form $\operatorname{Ir}_{5} \mathrm{Ce}$ precipitates in iridium alloys $[18,19]$, will leave the grain boundaries and diffuse to free surfaces to form cerium oxide (similar to the behavior of thorium). As with thorium, the diffusion of cerium from the grain boundaries and the dissolution of $\mathrm{Ir}_{5} \mathrm{Ce}$ precipitates would result in the unpinning of the grain boundaries causing anomalous surface grain growth and reduced impact ductility $[20,21]$.

In the last fiscal year, a report on the grain growth of DOP-40 alloys containing $20-40 \mathrm{ppm}$ Ce and $30-50 \mathrm{ppm}$ Th tested at $1330^{\circ} \mathrm{C}$ in an oxygen partial pressure of $13.3 \mathrm{mPa}\left(10^{-4}\right.$ torr) was completed [22]. The current report describes tests conducted at $1330^{\circ} \mathrm{C}$ using a lower oxygen partial pressure $\left(10^{-5} \mathrm{torr}, 1.3 \mathrm{mPa}\right)$ and compares the results with those from previous tests from both Ce-doped alloys and DOP-26. 
Table I. DOP-26 and Ce-Doped Iridium Alloys Tested in Low Pressures of Oxygen

\begin{tabular}{|c|c|c|c|c|c|}
\hline $\begin{array}{l}\text { Oxygen Pressure } \\
\qquad(\mathrm{mPa})\end{array}$ & $\begin{array}{l}\text { Temp. } \\
\left({ }^{\circ} \mathrm{C}\right)\end{array}$ & $\begin{array}{c}\text { DOP-26a } \\
\text { (old process) }\end{array}$ & $\begin{array}{c}\text { DOP-26a } \\
\text { (new process) }\end{array}$ & Ce-doped ${ }^{\mathrm{a}}$ & $\begin{array}{l}\text { Date of report } \\
\text { to DOE }\end{array}$ \\
\hline 1.3 & $\begin{array}{l}1330 \\
1280 \\
1230\end{array}$ & $\begin{array}{l}\text { ZR } \\
\text { ZR } \\
Z R\end{array}$ & $\begin{array}{l}\mathrm{D} 2, \mathrm{E} 2 \\
\mathrm{D} 2, \mathrm{E} 2 \\
\mathrm{D} 2, \mathrm{E} 2\end{array}$ & $\begin{array}{c}\mathrm{Ce}-2 \\
\mathrm{Ce}-3 \\
\mathrm{Ce}-3, \mathrm{E}-815\end{array}$ & $\begin{array}{l}4 / 24 / 92 \text { [ref. 10] } \\
6 / 25 / 93 \text { [ref. 11] } \\
8 / 29 / 94 \text { [ref. 12] }\end{array}$ \\
\hline 13.3 & $\begin{array}{l}1330 \\
1280 \\
1230\end{array}$ & $\begin{array}{c}\text { ZR } \\
\text { ZR,B706 } \\
\text { ZR,B706 }\end{array}$ & $\begin{array}{l}\text { D2,E2 } \\
\text { D2 } \\
\text { D2 }\end{array}$ & $\begin{array}{c}\mathrm{I} 1 \\
\mathrm{I} 1 \\
\mathrm{I1}, \mathrm{I}-103\end{array}$ & $\begin{array}{l}2 / 25 / 97 \text { [ref. 13] } \\
3 / 27 / 98 \text { [ref. 14] } \\
2 / 26 / 99 \text { [ref. 15] }\end{array}$ \\
\hline 13.3 & 1330 & & $\mathrm{D} 2$ & $\begin{array}{l}\text { I-102, I-103, } \\
\text { I-104, I-105 }\end{array}$ & $2 / 25 / 00$ [ref. 22$]$ \\
\hline 1.3 & 1330 & & D2 & $\begin{array}{l}\mathrm{I}-102, \mathrm{I}-103, \\
\mathrm{I}-104, \mathrm{I}-105\end{array}$ & this report \\
\hline
\end{tabular}

In this series of tests, specimens were cut from DOP-40 ingots denoted as $\mathrm{I}-102,103,104$, and 105 with Ce/Th compositions as listed in Table II. These ingots were fabricated from $500-\mathrm{g}$ heats using the old process [16]. Also included in this series of tests were specimens of the D2 DOP-26 ingot, fabricated by the new process. Since previous testing has shown that there is no significant difference in the oxygen compatibility of old and new-process DOP-26, the D2 specimens were used as controls in this series of tests.

Table II. Nominal dopant levels of DOP-40 (Ir-0.3\%W) alloys

\begin{tabular}{|c|c|c|}
\hline Alloy No. & Ce (wppm) & Th (wppm) \\
\hline I-102 & 20 & 40 \\
I-103 & 30 & 30 \\
I-104 & 30 & 40 \\
I-105 & 30 & 50 \\
\hline
\end{tabular}

All Ce/Th-doped samples used in this study were cut from rolled sheets and the D2 samples were cut from a fabricated "blank." The samples were recrystallized for $1 \mathrm{~h}$ at $1375^{\circ} \mathrm{C}$ in vacuum $\left(10^{-4} \mathrm{~Pa}\right.$ range) prior to oxygen annealing. Oxygen annealing was performed at $1330^{\circ} \mathrm{C}$ in a dynamically pumped tube furnacc having a base pressure of $4 \times 10^{-4}$ $\mathrm{Pa}\left(3 \times 10^{-6}\right.$ torr $)$. An oxygen leak valve, upstream from the samples, was adjusted so that the ion gage pressure halfway between the leak valve and the samples was $1.3 \times 10^{-3} \mathrm{~Pa}(1.3 \mathrm{mPa})$. The samples were hung on iridium wires in such a way as to separate them and provide for uniform flow of oxygen to all surfaces of all samples. Since several different annealing times wcre uscd, a furnace entry system was used that allowed for easy entry and exit of samples without temperature cycling of the furnace. Samples were grouped according to the time of exposure that each group would receive, and all were placed in the furnace at the beginning of the test. After each allotted time ( 1 week, 1 month, etc.), the furnace was opened and one group removed. The maximum exposure time of the oxygen anneals was approximately $3000 \mathrm{~h}$ (4 months).

Optical metallography techniques [16] of polishing, etching, and measuring grain sizes were used to determine the grain growth as a function of exposure time. Grain sizes were measured by the method of linear intercepts in both the short transverse (ST) and long transverse (LT) directions with respect to the rolling direction. Grain sizes were also measured in the LT direction as a function of depth into the specimen in order to determine the degree of anomalous growth of near-surface grains. The confidence limits of the data are indicated by the number of intercepts counted for each data point (recorded in parentheses in the tables). 
Figure 1 shows the average grain size in both the ST and LT directions for DOP-40 heats $1-102$ through I-105 exposed for up to $3000 \mathrm{~h}$ at $1330^{\circ} \mathrm{C}$ in an oxygen partial pressure of $1.3 \mathrm{mPa}$. Data for the D2 (new process) DOP-26 heat are included for comparison. Although the DOP-40 alloys used in this study were prepared using the old fabrication process, their comparison to new process D2 material is justified since past studies of old- and new-process DOP-26 at 1230,1280 , and $1330^{\circ} \mathrm{C}$ in oxygen levels of 1.3 and $13.3 \mathrm{mPa}$ have shown no difference in their oxygen compatibility [10-16]. Figure la shows that grain growth of all four Ce/Th-doped alloys is comparable to that of the D2 (new process) DOP-26 material in the ST direction. At this low oxygen partial pressure, very little grain growth was noted. In Fig. $\mathrm{Ib}$, grain sizes for the Ce/Th-doped alloys are slightly higher than for the DOP-26 alloy. This result was previously noted for the 11 heat of DOP-40 [15]. Initially, the Ce/Th-doped alloys may experience slightly higher grain growth rates than DOP-26 in the LT direction, but after about two weeks time the data indicates that the rates of grain growth are comparable for both the DOP-40 and DOP-26 alloys $(15,22)$.

(a)

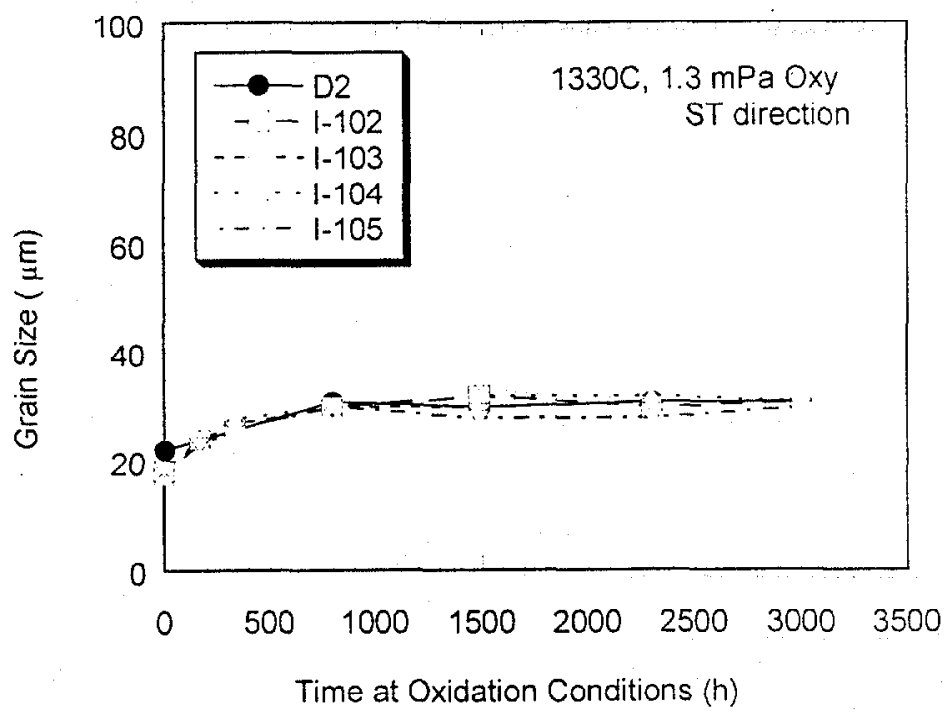

(b)

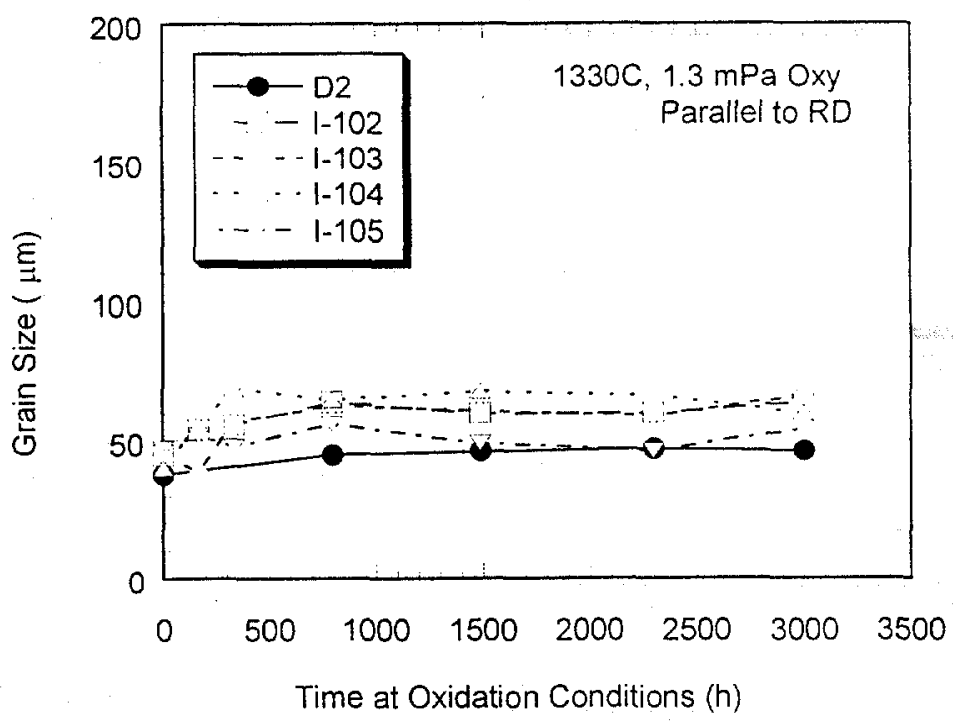

Fig. 1. Grain size as a function of time of exposure at $1330^{\circ} \mathrm{C}$ in an oxygen partial pressure of $1.3 \mathrm{mPa}$ for four $\mathrm{Ce} / \mathrm{Th}$-doped DOP-40 alloys and the newprocess DOP-26 D2 alloy in the (a) ST and (b) LT direction with respect to the rolling direction. 
Figure 2 compares the average grain sizes of alloys D2 and I-102 through I-105 exposed at $1330^{\circ} \mathrm{C}$ in an oxygen partial pressure of $1.3 \mathrm{mPa}$ with data for the same alloys exposed at the same temperature but at the higher oxygen partial pressure of $13.3 \mathrm{mPa}$ [22]. The increase in grain size for the $13.3 \mathrm{mPa}$ exposure compared to the $1.3 \mathrm{mPa}$ exposure is consistent with results observed previously for the DOP-26 alloy $[15,16]$.

(a)

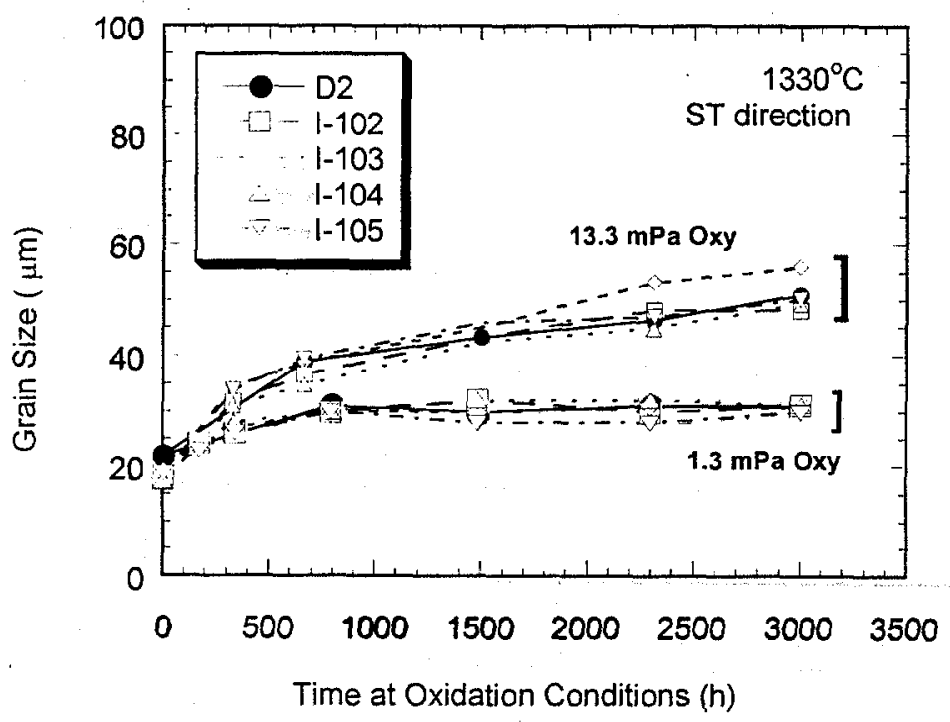

(b)

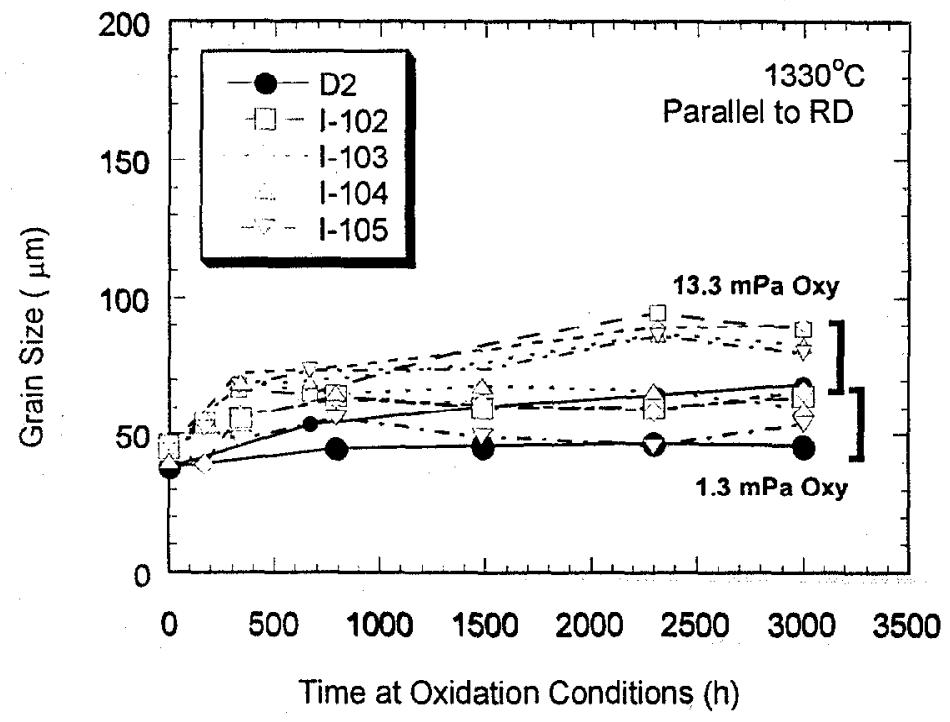

Fig. 2. Comparison of grain size as a function of time of exposure at $1330^{\circ} \mathrm{C}$ in two different oxygen partial pressures $(1.3$ and $13.3 \mathrm{mPa})$ for the /Th-doped DOP-40 alloys and the new-process DOP-26 D2 alloy in the (a) ST and (b) LT direction with respect to the rolling direction. 
Figures 3-7 show grain sizes in the LT direction as a function of depth into the specimen for the alloys used in this study. Plotting the grain size in this manner allows one to determine the tendency for anomalous growth of near-surface grains. More rapid growth of near-surface grains indicates that the Th and/or Ce are diffusing out of the material and are therefore unavailable for pinning of the grain boundaries [20,21]. The D2 DOP-26 alloy was previously tested at $1330^{\circ} \mathrm{C}$ in $1.3 \mathrm{mPa}$ oxygen [10]; the current results for this alloy, shown in Fig. 3, are comparable to those reported previously. The current data shows no tendency for growth of near-surface grains in D2, with grain sizes remaining below approximately $55 \mu \mathrm{m}$ (comparable to the overall average grain size in the LT direction) even after $3000 \mathrm{~h}$ of exposure.

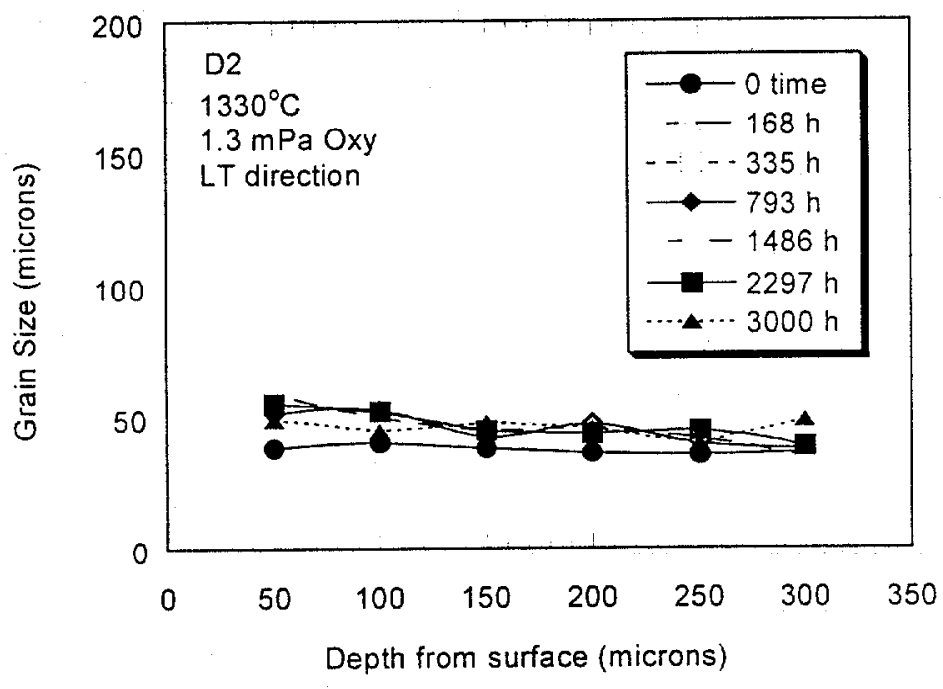

Fig. 3. Grain size in the LT direction as a function of depth below the surface of the sample and time of exposure for the D2 DOP -26 alloy annealed at $1330^{\circ} \mathrm{C}$ in an oxygen partial pressure of $1.3 \mathrm{mPa}$.

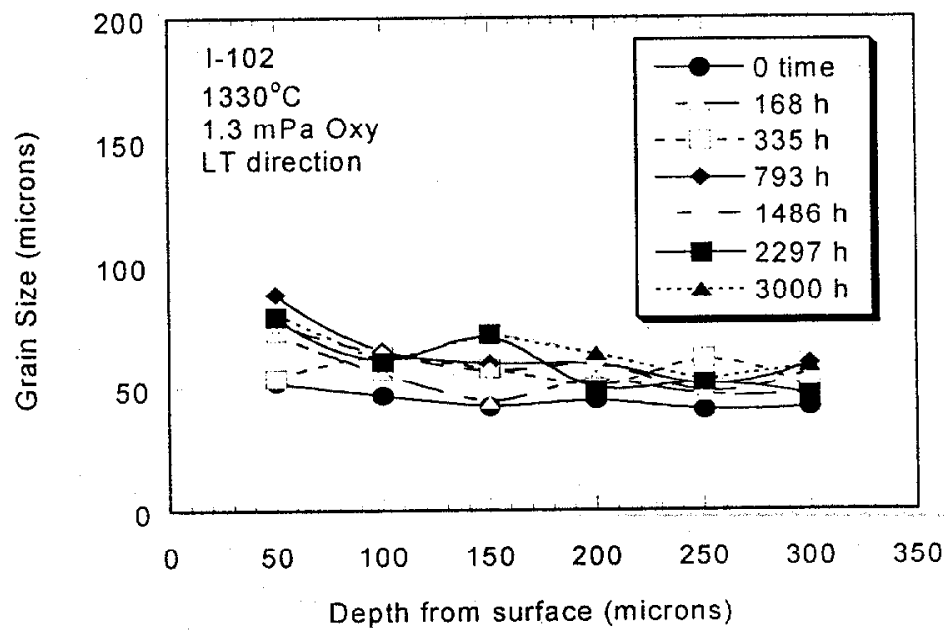

Fig. 4. Grain size in the LT direction as a function of depth below the surface of the sample and time of exposure for the $\mathrm{Ce} / \mathrm{Th}$-doped $\mathrm{I}-102$ alloy annealed at $1330^{\circ} \mathrm{C}$ in an oxygen partial pressure of $1.3 \mathrm{mPa}$. 


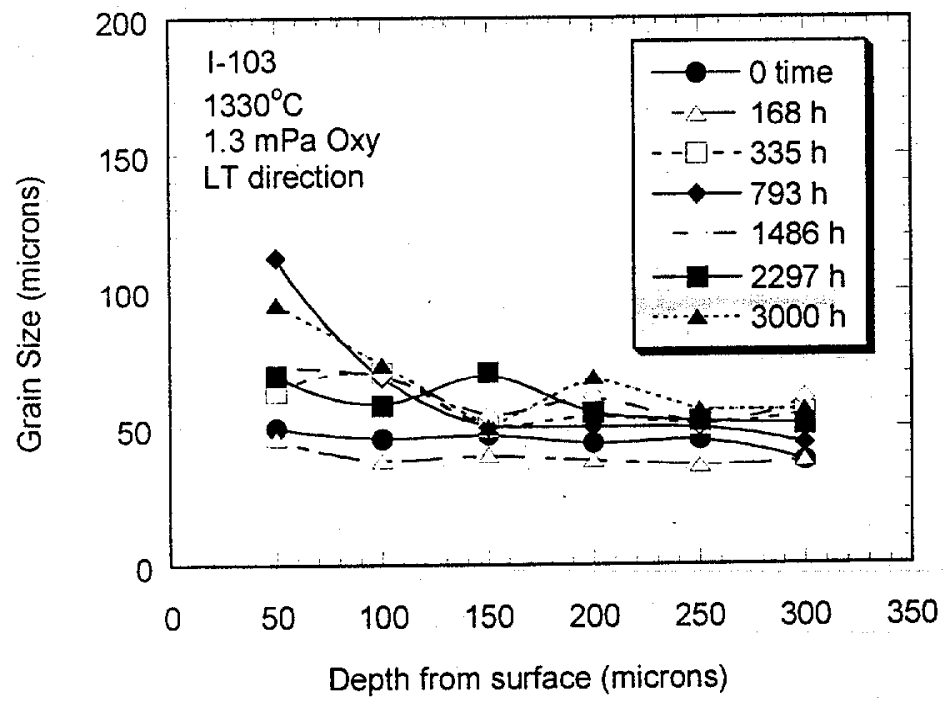

Fig. 5. Grain size in the LT direction as a function of depth below the surface of the sample and time of exposure for the $\mathrm{Ce} / \mathrm{Th}$ doped $1-103$ alloy annealed at $1330^{\circ} \mathrm{C}$ in an oxygen partial pressure of $1.3 \mathrm{mPa}$.

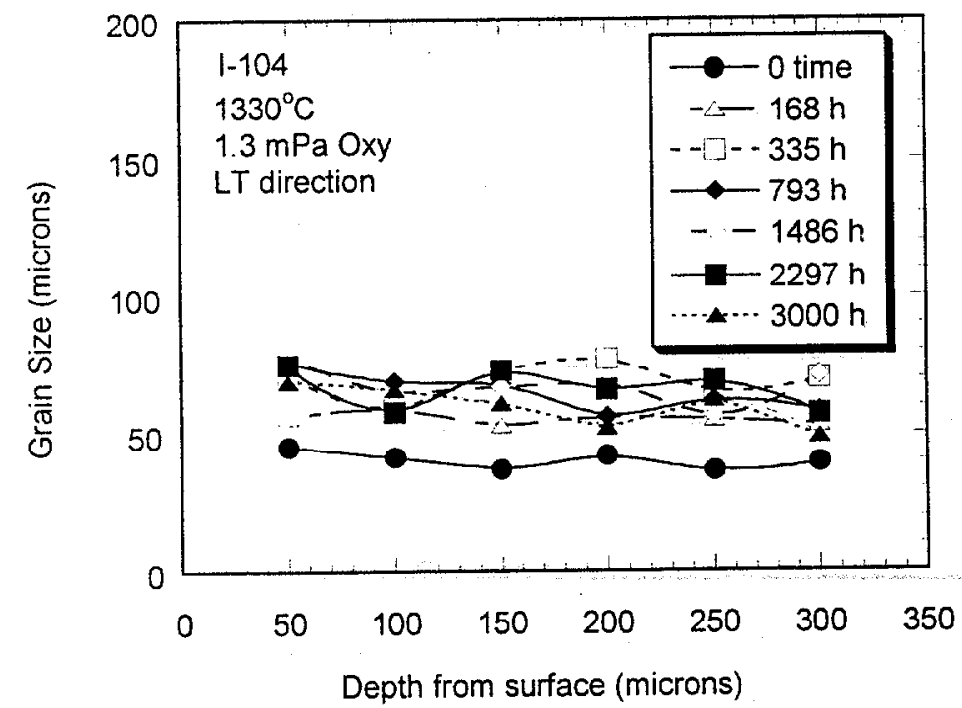

Fig. 6. Grain size in the I.T direction as a function of depth below the surface of the sample and time of exposure for the $\mathrm{Ce} / \mathrm{Th}$ doped $\mathrm{I}-104$ alloy annealed at $1330^{\circ} \mathrm{C}$ in an oxygen partial pressure of $1.3 \mathrm{mPa}$. 


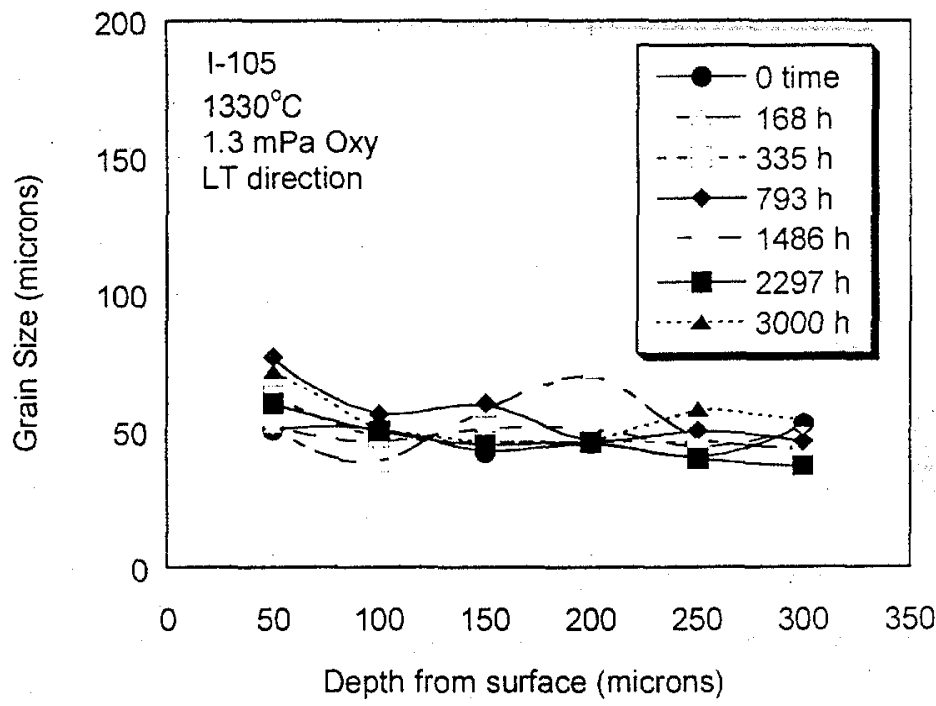

Fig. 7. Grain size in the LT direction as a function of depth below the surface of the sample and time of exposure for the $\mathrm{Ce} / \mathrm{Th}$ doped $1-105$ alloy annealed at $1330^{\circ} \mathrm{C}$ in an oxygen partial pressure of $1.3 \mathrm{mPa}$.

At this low oxygen partial pressure, alloys $1-102$ through $1-105$ also showed almost no tendency for anomalous grain growth of the near-surface grains. After $3000 \mathrm{~h}$ of exposure their near-surface $(50-150 \mu \mathrm{m}$ below the surface) grain sizes ranged from approximately 70 to $95 \mu \mathrm{m}$ (see Figs. 4-7). This is shown more clearly in Figs. 8-11 where the 0 and $3000 \mathrm{~h}$ grain sizes are plotted as a function of depth below the surface. As noted in previous reports [15,22], grain sizes in the LT direction in the DOP-40 alloys are slightly larger than those measured in the DOP-26. A possible reason for this is the smaller mass of Ce relative to Th which would result in faster diffusion. Considering the data at $1330^{\circ} \mathrm{C}$ in oxygen partial pressures of both 1.3 and $13.3 \mathrm{mPa}$ (and considering the standard deviations of the data), there does not appear to be any difference between the four $\mathrm{Ce} / \mathrm{Th}$-doped alloys in terms of their tendency for near-surface grain growth (see Figs. 8-11). In addition, their near-surface grain growth tendency is comparablc to that of the D2 DOP-26 alloy (see Fig. 12).

In summary, oxygen compatibility studies were conducted on specimens from the I-102 through I-105 ingots of DOP-40 in an oxygen partial pressure of $1.3 \mathrm{mPa}$ at a temperature of $1330^{\circ} \mathrm{C}$ for times up to $3000 \mathrm{~h}$. Specimens of the newprocess D2 DOP-26 material were included for comparison purposes. In terms of average grain size and grain growth rates in the ST direction as a function of time, the DOP-40 alloys are comparable to DOP-26. In the LT direction, although the starting grain sizes of the DOP-40 alloys were comparable to that of the DOP- 26 material, average grain sizes as a function of time were slightly larger for the $\mathrm{Ce} / \mathrm{Th}$-doped DOP-40 alloys. This difference has been attributed to the possible faster diffusion rate of $\mathrm{Ce}$ as compared to Th. After about two weeks time the data indicate that the rates of grain growth are comparable for both materials. At the low partial pressure of oxygen used in this series of tests, neither DOP-26 nor DOP-40 showed any strong tendency for anomalous growth of near-surface grains. 


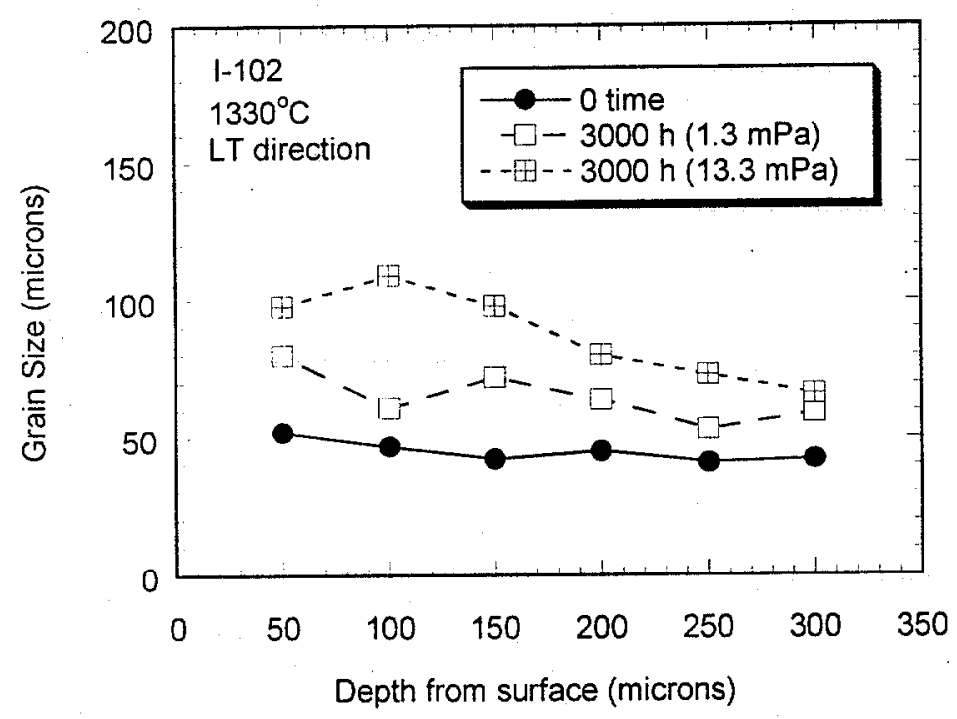

Fig. 8. Comparison of grain size as a function of depth below the surface of the sample for the I-102 alloy annealed at $1330^{\circ} \mathrm{C}$ in oxygen partial pressures of 1.3 and $13.3 \mathrm{mPa}$.

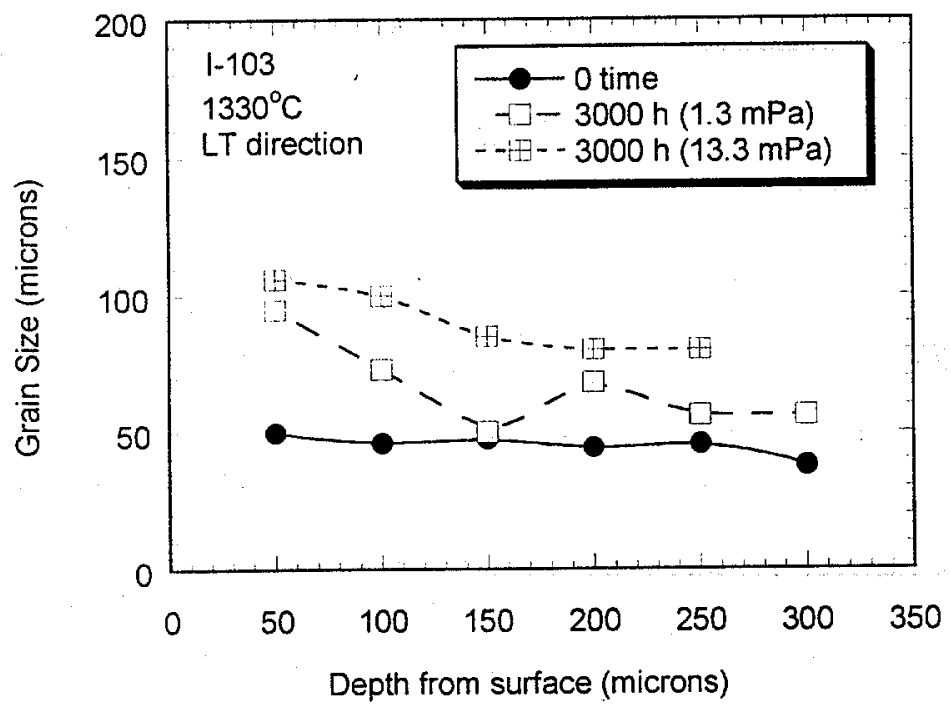

Fig. 9. Comparison of grain size as a function of depth below the surface of the sample for the $\mathrm{I}-103$ alloy annealed at $1330^{\circ} \mathrm{C}$ in oxygen partial pressures of 1.3 and $13.3 \mathrm{mPa}$. 


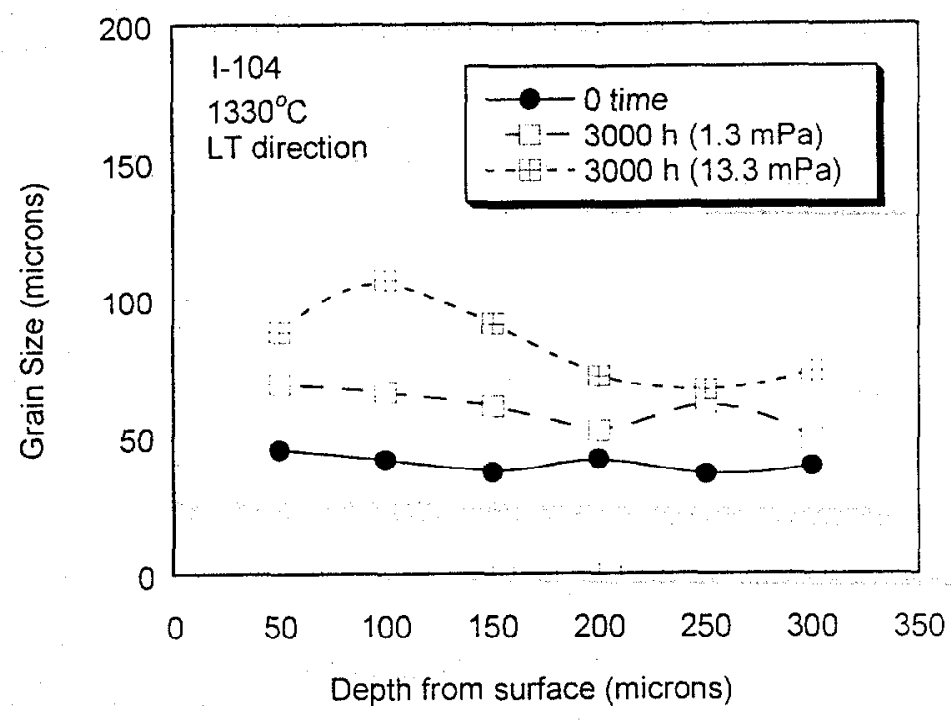

Fig. 10. Comparison of grain size as a function of depth below the surface of the sample for the $1-104$ alloy annealed at $1330^{\circ} \mathrm{C}$ in oxygen partial pressures of 1.3 and $13.3 \mathrm{mPa}$.

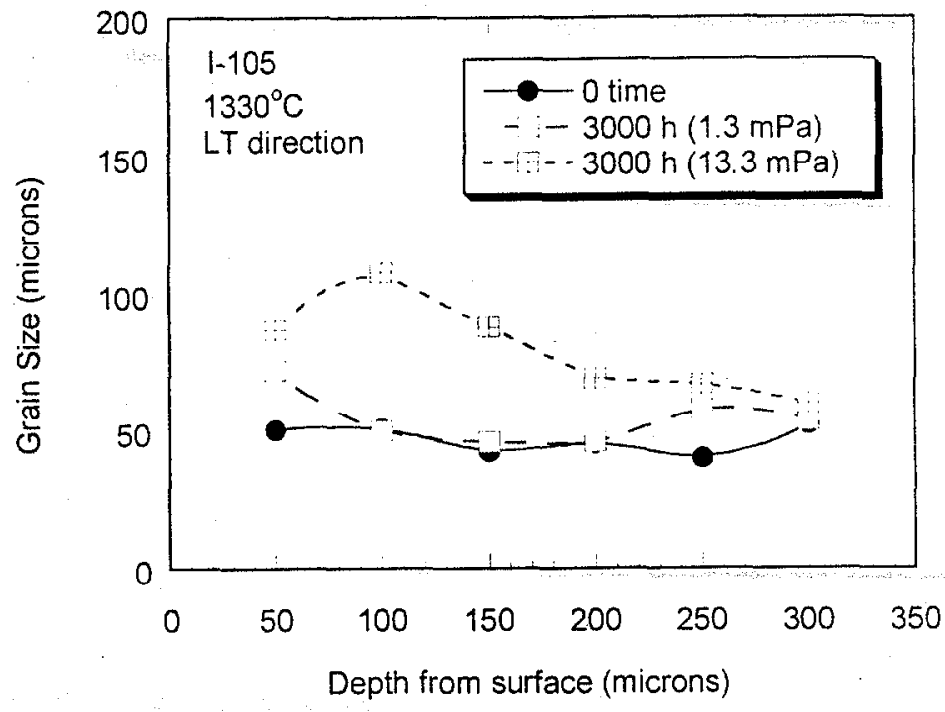

Fig. 11. Comparison of grain size as a function of depth below the surface of the sample for the I-105 alloy annealed at $1330^{\circ} \mathrm{C}$ in oxygen partial pressures of 1.3 and $13.3 \mathrm{mPa}$. 


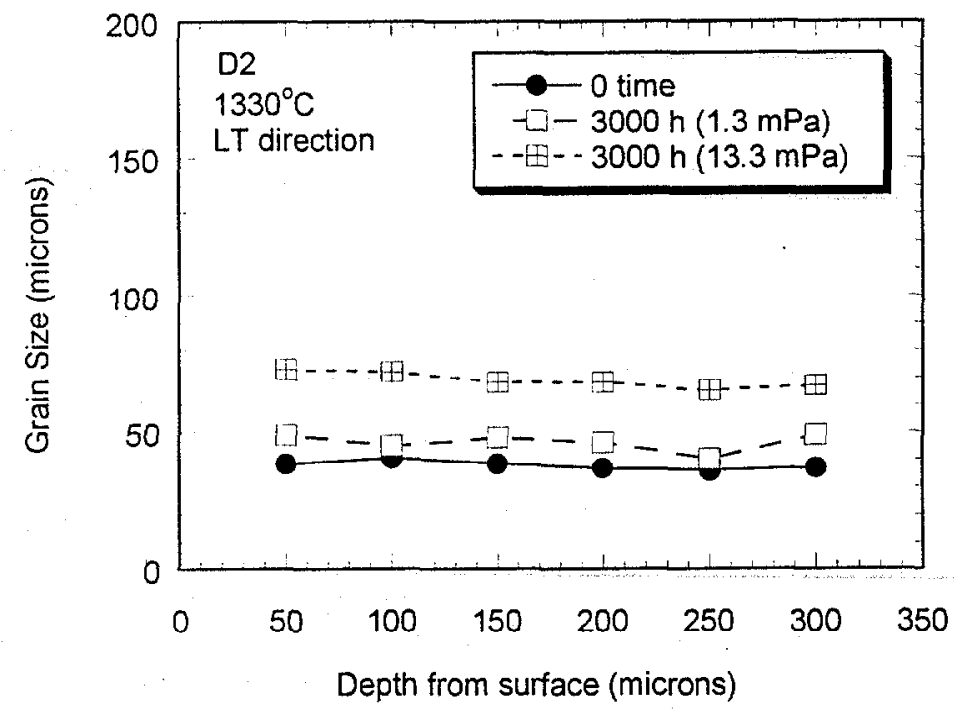

Fig. 12. Comparison of grain size as a function of depth below the surface of the sample for the D2 DOP-26 alloy annealed at $1330^{\circ} \mathrm{C}$ in oxygen partial pressures of 1.3 and $13.3 \mathrm{mPa}$.

\subsubsection{References}

1. C. T. Liu and H. Inouye, Development and Characterization of an Improved Ir-0.3\% $W$ Alloy for Space Radioisotopic Heat Sources, ORNL-5290 (1977), available from NTIS, U.S. Department of Commerce, Springfield, VA 22161.

2. C. L. White, R. E. Clausiñg and L. Heatherly, Metall. Trans. A 10, 683 (1979).

3. T. B. Massalski, editor-in-chief, Binary Alloy Phase Diagrams, (ASM, Metals Park, OH, 1986).

4. C. T. Liu and S. A. David, Weld Metal Grain Structue and Mechanical Properties of Iridium Alloy DOP-26, ORNL-5857, Oak Ridge National Laboratory, Oak Ridge, TN, August 1982.

5. E. P. George, p. 10 of "Quarterly Technical Progress Report of Radioisotope Thermoelectric Generator Materials Production and Technology Tasks for April through June 1995," ORNL/CF-95/66, Oak Ridge National Laboratory, Oak Ridge, TN, July 16, 1995.

6. J. W. Cohron and E. P. George, "Comparison of the Grain Growth Behavior of DOP-Ce and DOP-26 Iridium Alloys," attachment to letter from J. P. Moore to W. J. Barnett, Sept. 29, 1995.

7. A. N. Gubbi, E. P. George, E. K. Ohriner, and R. H. Zee, "Influence of Cerium Additions on High-TemperatureImpact Ductility and Fracture Behavior of Iridium Alloys," Metall. Mater. Trans. 28A, 2049-57 (1997).

8. C. G. McKamey, J. W. Cohron, and E. P. George, "Comparison of the Grain Growth Behavior of DOP-40 and DOP-26 Iridium Alloys," attachment to letter from J. P. Moore to W. J. Barnett, April 30, 1997. 
9. E. P. George, E. K. Ohriner, and E. H. Lee, "Sensitivity of the High-Temperature Impact Ductility of DOP-40 Iridium to Small Changes in Ce and Th Concentration," attachment to letter from J. P. Moore to W. J. Barnett, Oct. 1998.

10. C. G. McKamey, E. H. Lee, E. P. George, and E. K. Ohriner, "Oxygen Compatibility of DOP-26 Iridium," attachment to letter from J. P. Moore to W. J. Barnett, April 24, 1992.

11. C. G. McKamey, A. N. Gubbi, E. H. Lee, E. P. George, and E. K. Ohriner, "Oxygen Compatibility of DOP-26, $\mathrm{Ce}-$, Lu-, and Y-Doped Iridium Alloys at $1280^{\circ} \mathrm{C}$ and $1.3 \mathrm{mPa}$ Oxygen Pressure," attachment to letter from J. P. Moore to W. J. Barnett, June 25, 1993.

12. C. G. McKamey, A. N. Gubbi, E. H. Lee, E. P. George, and E. K. Ohriner, "Compatibility of Old- and NewProcess DOP-26 and Cerium-Doped Iridium Alloys at $1230^{\circ} \mathrm{C}$ and $1.3 \mathrm{mPa}$ Oxygen Pressure," attachment to letter from J. P. Moore to W. J. Barnett, Aug. 29, 1994.

13. C. G. McKamey, J. W. Cohron, and E. P. George, "Oxygen Compatibility Studies of Old- and New-Process DOP-26 and Ce-Doped DOP-40 Iridium Materials at $1330^{\circ} \mathrm{C}$ and an Oxygen Partial Pressure of $13.3 \mathrm{mPa"}$, attachment to letter from J. P. Moore to W. J. Barnett, Feb. 25, 1997.

14. C. G. McKamey and E. P. George, "Oxygen Compatibility of DOP-26 and DOP-40 Iridium Alloys at $1280^{\circ} \mathrm{C}$ and an Oxygen Partial Pressure of $13.3 \mathrm{mPa}$ ", attachment to letter from J. P. Moore to W. J. Barnett, March 27, 1998.

15. C. G. McKamey, E. H. Lee, J. W. Cohron, A. N. Gubbi, and E. P. George, "High-Temperature Low-Pressure Oxygen Compatibility of DOP-26 Iridium Alloys," attachment to letter from J. P. Moore to W. J. Barnett, Feb. 26, 1999.

16. C. G. McKamey, A. N. Gubbi, Y. Lin, J. W. Cohron, E. H. Lee, and E. P. George, Grain Growth Behavior and High-Temperature High-Strain-Rate Tensile Ductility of Iridium Alloy DOP-26, ORNL-6935, Oak Ridge National Laboratory, Oak Ridge, TN, April 1998.

17. C. G. McKamey, E. P. George, E. H. Lee, and E. K. Ohriner, "Effect of Grain Size on Impact Ductility in Ce+Thdoped DOP-40 Iridium Alloys," attachment to letter from J. P. Moore to W. J. Barnett, March 30, 2000.

18. J. J. Liao, Ph.D. Thesis, Auburn University, 1992.

19. J. W. Cohron, C. G. McKamey, and E. P. George, "Comparison of the Grain Growth Behavior of DOP-40 and DOP-26 Iridium Alloys," attachment to letter from J. P. Moore to W. J. Barnett, May 31, 1996.

20. C. L. White and C. T. Liu, Acta Metall. 29, 301 (1981).

21. C. G. McKamey, E. H. Lee, J. W. Cohron, and E. P. George, "The Effect of Low-Pressure Oxygen Exposure on the High-Temperature Tensile Impact Ductility of a Thorium-Doped Iridium Alloy," Scripta Mater. 35(2), 18185 (1996).

22. C. G. McKamey, E. H. Lee, and E. P. George, "Oxygen Compatibility of Ce-doped Iridium Alloys at $1330^{\circ} \mathrm{C}$ and an Oxygen Partial Pressure of $13.3 \mathrm{mPa}$," attachment to letter, J. P. Moore to W. J. Barnett, Feb. 25, 2000. 


\subsection{Milliwatt Generator Components}

\subsubsection{Background}

A milliwatt generator has been developed by Hi-Z Technology, Inc. of San Diego, California. When powered by a 1.1 watt source, the generator has an output of about 40 milliwatt as long as the system is dynamically pumped to a vacuum level below about 10 millitorr. Above this pressure, the thermal conductivity of the insulation in the generator becomes high enough to divert energy away from the thermoelectric module in the generator which causes a significant reduction in electrical output. Maintaining a low internal generator pressure could be easily achieved in deep space applications by venting the generator to space. On the surface of some planets such as Mars, however, the generator would have to operate in a sealed condition to prevent surface gasses from increasing the insulation thermal conductivity and thereby lowering the electrical output.

Therefore, successful use on the surface of Mars requires that the generator be evacuated prior to launch and then sealed off. If, however, components within the generator outgas at operating temperatures, the resulting buildup of gasses in the sealed generator could increase the pressure within the generator and thereby lower the electrical output. This potential problem was of special concern because the desired lifetime of the generator was 20 years during which time outgassing products could accumulate.

\subsubsection{Thermogravimetric Analysis Results}

Because of the above concern, an effort was initiated to perform thermogravimetric analysis on some system components and vacuum outgassing studies on other components such as the insulation. Table 1 lists the generator materials of interest.

Table 1. Milliwatt Generator Components and Tests Either Conducted or In Progress

\begin{tabular}{|c|l|l|c|l|}
\hline Item \# & \multicolumn{1}{|c|}{ Material } & \multicolumn{1}{|c|}{ Analysis Type } & \multicolumn{1}{c|}{$\begin{array}{c}\text { Test } \\
\text { Temperature }{ }^{\circ} \mathbf{C}\end{array}$} & \multicolumn{1}{c|}{ Status } \\
\hline \hline 1 & Cured Trabond 2212 Epoxy & TGA ${ }^{*}$ & 240 & Complete \\
\hline 2 & Partially Cured 2212 Epoxy & TGA & 52 & Complete \\
\hline 3 & $\begin{array}{l}\text { BiTe (H2P-211-1) Thermoelectric } \\
\text { Module }\end{array}$ & TGA & 255 & Complete \\
\hline 4 & Kapton 200KJ & TGA & 246 & Complete \\
\hline 5 & Insulation** & Vacuum Outgassing & 250 & In-Progress \\
\hline
\end{tabular}

* Thermogravimetric Analysis

** The insulation consists of alternate layers of Cryotherm 1303 which is unbonded microfiber paper and aluminized Kapton (HN) film.

Figures 1-4 show the weight change in vacuum of four materials at the temperatures listed in Table 1 . In general, the samples were heated at a rate of 1-2 degrees centigrade per minute up to the test temperature. Figure 1 shows the weight change of fully cured Trabond 2212 epoxy with time. In this case the epoxy was heated to about $160^{\circ} \mathrm{C}$ and held for about 24 hours before heating the rest of the way to $240^{\circ} \mathrm{C}$. Over the next 48 hours the epoxy lost about $3.5 \%$ of its weight, and the loss rate was still substantial at the end of the time. Hi-Z has now decided to change the design so that this epoxy would no longer be needed in the generator. 


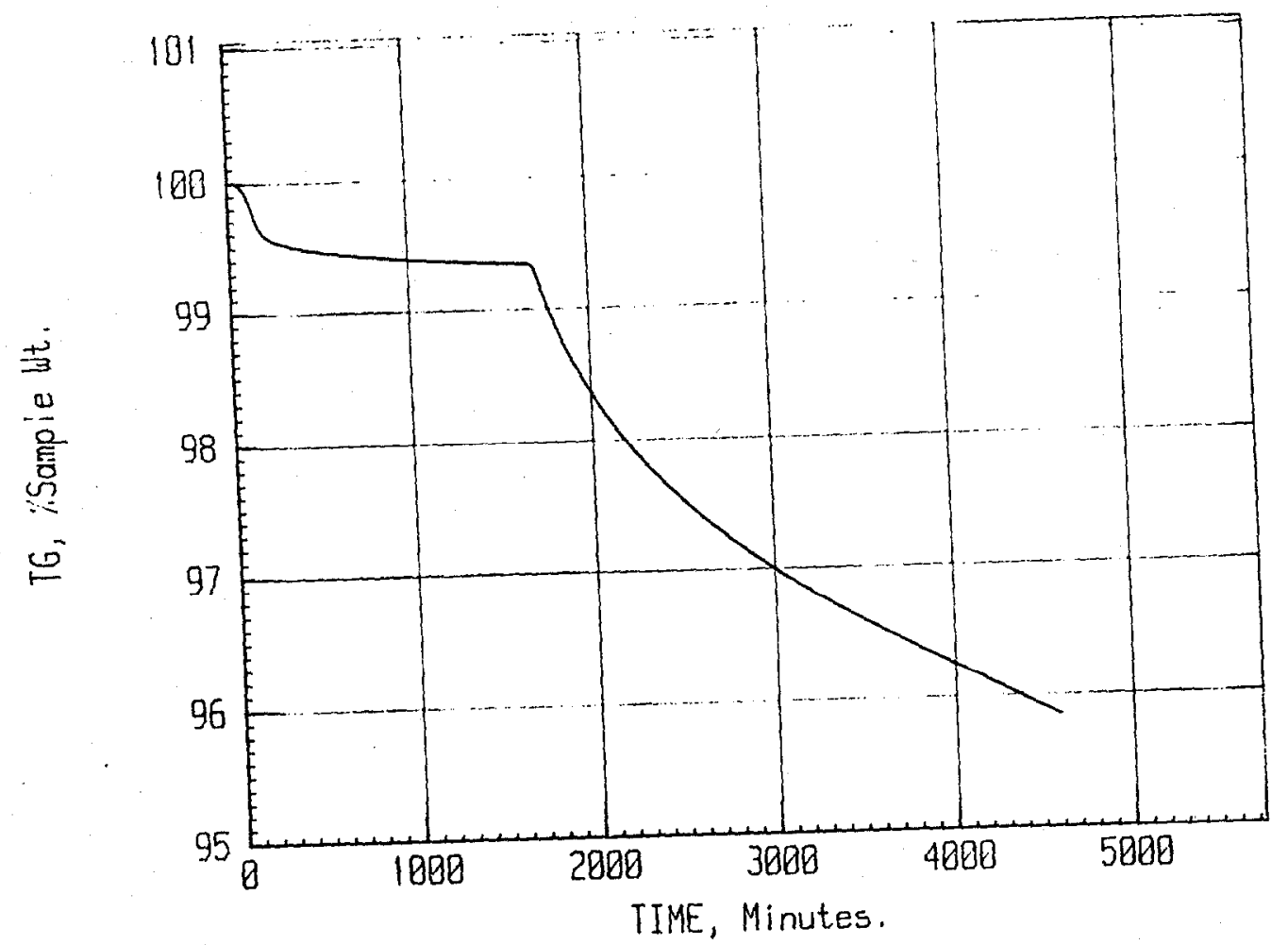

Fig. 1. TGA results in vacuum on cured Trabond 2212 Epoxy showing weight loss with time at $160^{\circ} \mathrm{C}$ and $240^{\circ} \mathrm{C}$.

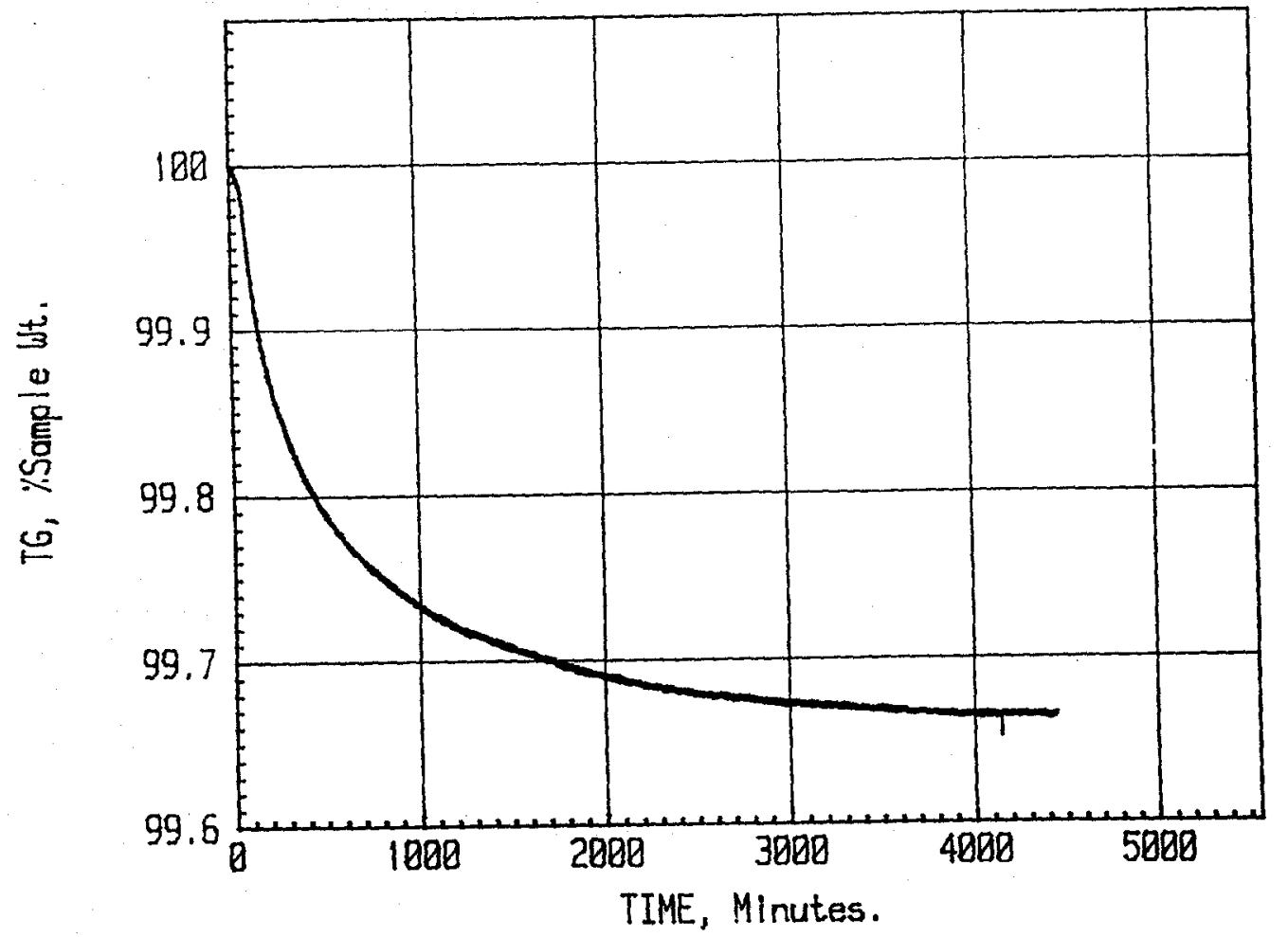

Fig. 2. TGA results on partially cured Trabond 2212 Epoxy showing weight loss at $52^{\circ} \mathrm{C}$ in vacuum. 


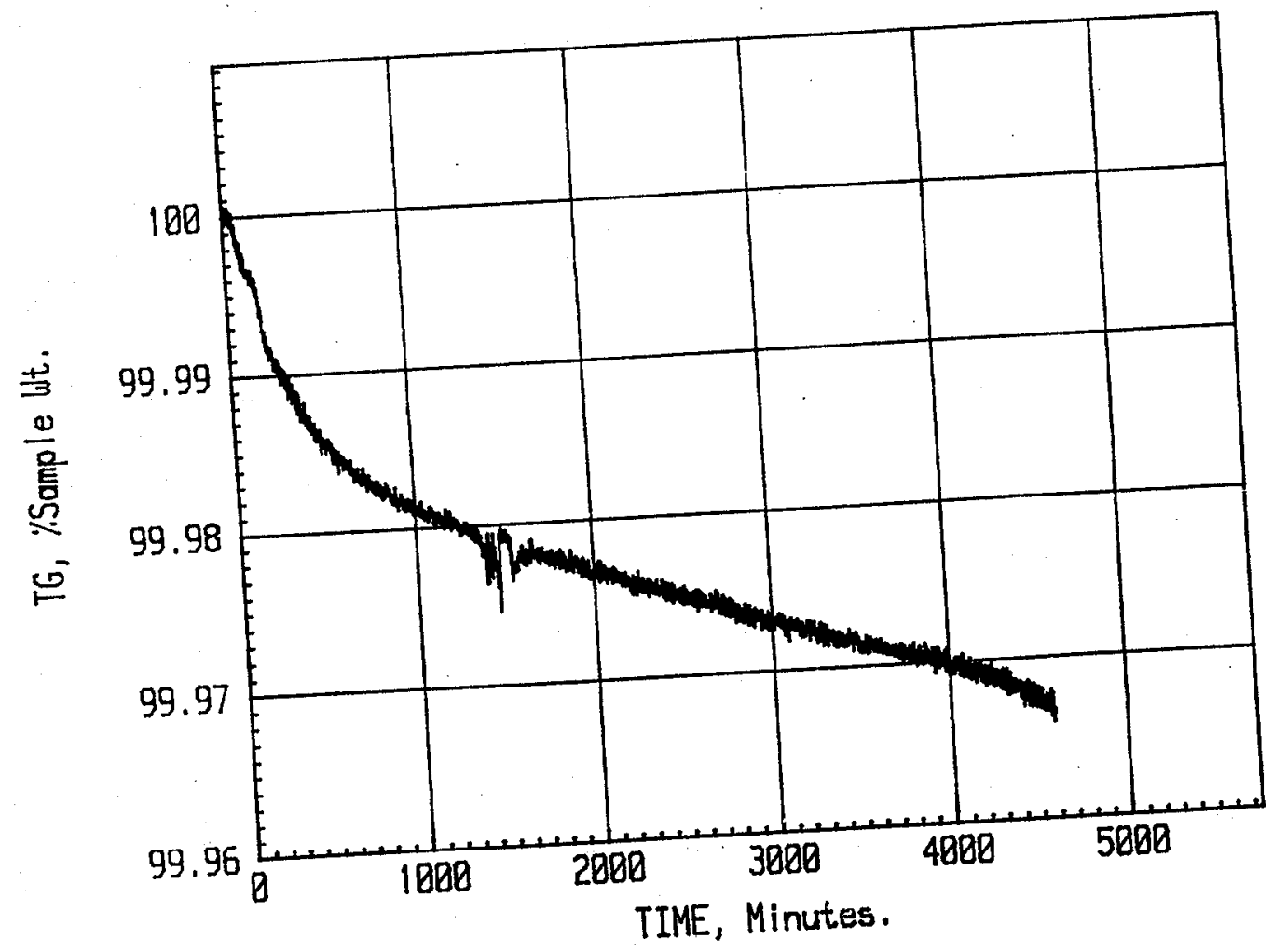

Fig. 3. TGA results on $\mathrm{BiTe}$ at $255^{\circ} \mathrm{C}$ in vacuum.

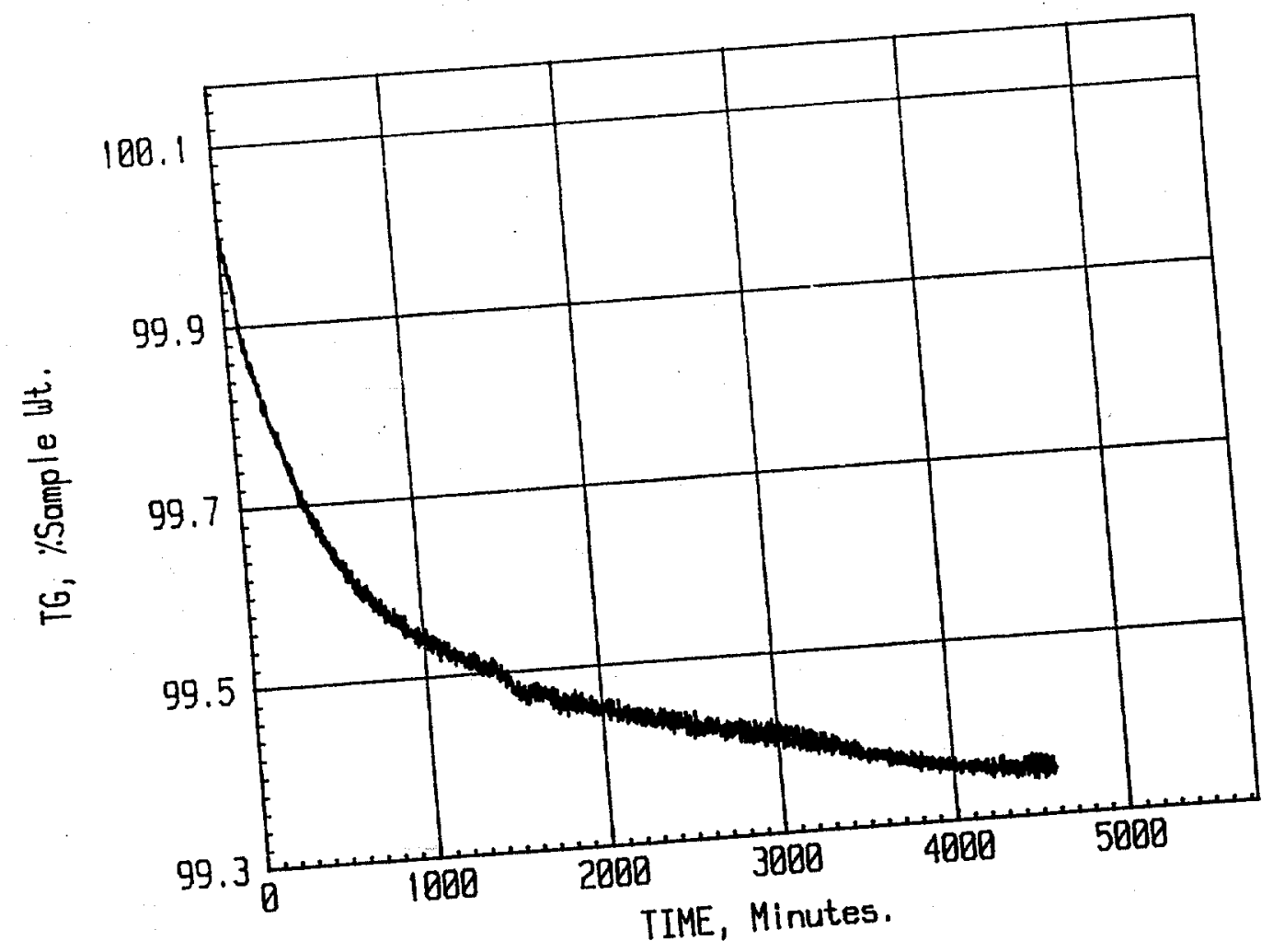

Fig. 4. TGA results on Kapton $200 \mathrm{KJ}$ at $246^{\circ} \mathrm{C}$ in vacuum. 
Figure 2 shows the weight change of the partially cured epoxy with time at a temperature of $52^{\circ} \mathrm{C}$. Although the sample lost about $0.33 \%$ of its weight in 72 hours, the weight had become stable by then. Therefore, the use of this material on the cold end of the thermoelectric module appears feasible at least from the standpoint of outgassing in operation.

Weight change of BiTe thermoelectric material is shown in Figure 3. In 72 hours of exposure to a vacuum, the material lost $0.033 \%$ of its weight, and the weight loss had not stopped at the end of the run. Hi-Z has now performed a longerduration weight loss test on similar material. The ORNL data is in excellent agreement with the $\mathrm{Hi}-\mathrm{Z}$ data up to 72 hours. The Hi-Z data shows that weight becomes constant after an exposure of about one week.

Figure 4 indicates a weight loss of $0.57 \%$ for Kapton $200 \mathrm{KJ}$ in 72 hours. At the end of that time the rate of weight loss is decreasing. Possibly the weight would stabilize with longer exposurcs.

\subsubsection{Vacuum Outgassing Tests on Insulation}

Figure 5 shows a diagram of the small high-vacuum system that will be used to assess the potential influence of insulation outgassing on internal generator pressure and to possibilities for pre-outgassing the entire insulation package prior to sealing it insidc a generator. The vacuum system consists of a stain less steel chamber mounted above a manifold. Included is a turbo-molecular pump, mechanical pump, high vacuum valve between the chamber and manifold, a residual gas analyzer (RGA), and a valve for admitting argon. In addition, there is a high vacuum valve (not shown) between the RGA and system manifold. The intent is to outgas the vacuum system and then to measure the system prcssure rise with time after the valve between the turbo-molecular pump and manifold is closed. After establishing a baseline for an empty system, an insulation sample would be placed in the system chamber and the influence of insulation outgassing on system pressure would be determined.

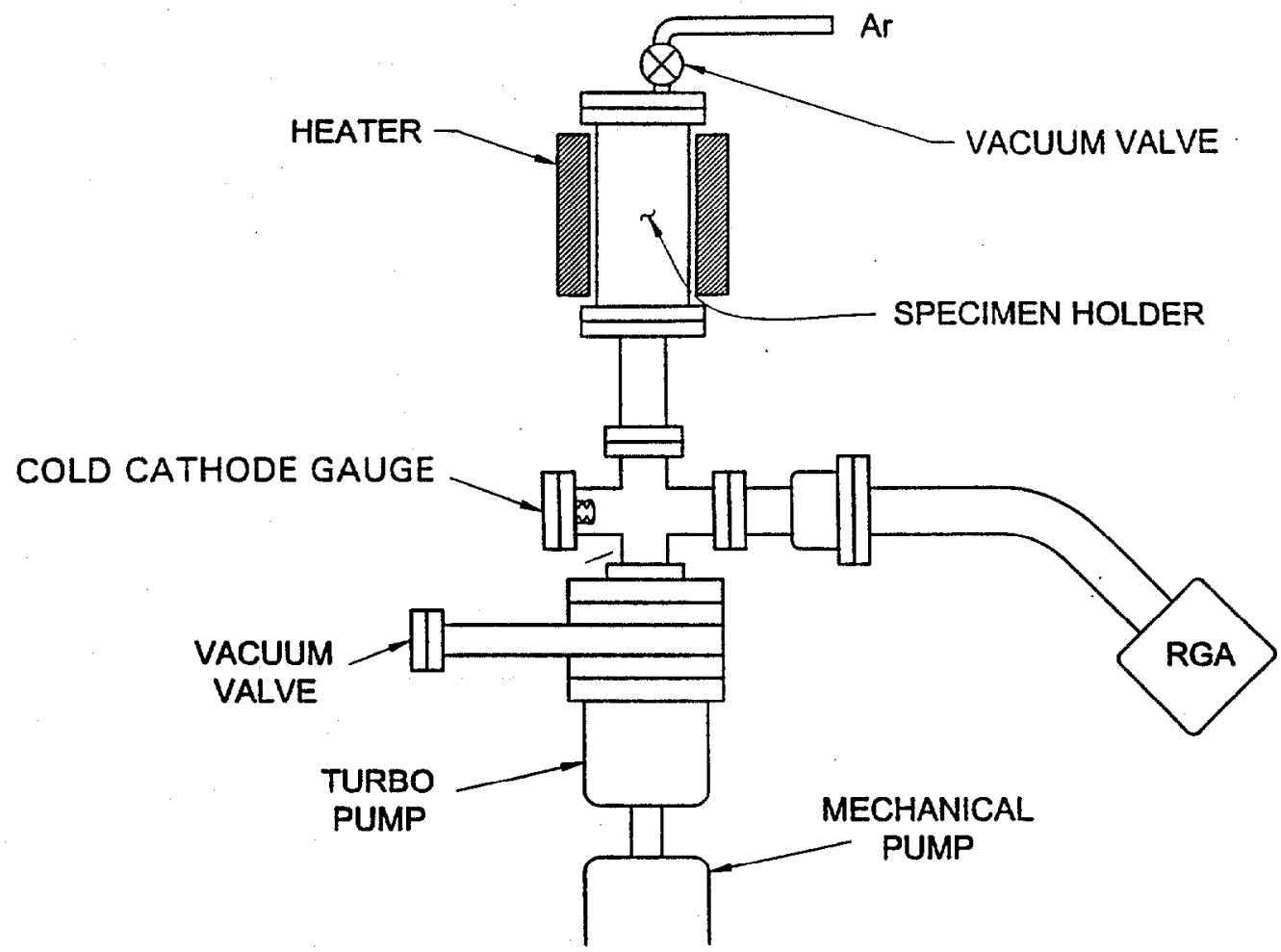

Fig. 5. High vacuum system used for insulation outgassing studies. A vacuum valve in the line to the RGA is not shown. 
Two runs were made to establish a baseline for the system performance prior to making an attempt to evaluate the insulation. These two runs were separated by several days after which the system was outgassed with the chamber temperature near $250^{\circ} \mathrm{C}$ and that of the manifold near $190^{\circ} \mathrm{C}$. During this period of outgassing, the RGA indicated that there was very little water in the system. After this stage of system outgassing, the manifold temperature was lowered to about $70^{\circ} \mathrm{C}$ and powcr sources adjusted to maintain the chamber near $250^{\circ} \mathrm{C}$. At this time the system pressure was $3.5 \times 10^{-9}$ torr. The high vacuum valve was closed to isolate the chamber from the pumping system. Chamber pressure and temperature were then tracked as a function of time. System pressure increased to about $5 \times 10^{-5}$ torr over the next 30 hours and then remained constant for over three days. Concern for the filament in the RGA led to a decision to turn the RG $\Lambda$ off. This led to a pressure increase to about $1 \times 10^{-4}$ over the next day. This is consistent with previous experiences and indicates the presence of gasses which are mobile and can move around depending on the temperatures of the various system components. The chamber temperature was then lowered to room temperature. RGA analysis during this system test indicated that no water was present which indicates that the system was vacuum tight. A decision was made to prepare and install a test sample of insulation into the chamber.

\subsubsection{Insulation Specimen Description}

The insulation in the milliwatt generator consisted of alternate layers of aluminized Kapton and Cryotherm paper. Using handling instructions from $\mathrm{Hi}-\mathrm{Z}$ personnel, a test sample was made by cutting 2.5 inch wide strips of the two materials and then winding the strips into a loosely packed roll. The roll was held together by using narrow strips of the aluminized Kapton as string. A long strip of the aluminized Kapton was tied to the roll for lowering it into the test chamber. The roll contained 500 square inches each of the two materials. This rolled sample was inserted into the test chamber. Following system evacuation, temperatures were increased to outgas the sample. The results of the sample outgassing and chamber pressures following closing of the high vacuum valve will be reported in the next technical report of the RPS Program. 


\subsection{TARGET DEVELOPMENT}

The target development effort has been broken into several phases in order to develop data leading to production targets. Figure 1 illustrates the various phases. The dosimeter targets were irradiated in several locations within the ATR and in several spectral environments. The objective was to use a small amount of $\mathrm{NpO}_{2}$ to examine the ${ }^{236} \mathrm{Pu}$ content of an unperturbed influence flux while characterizing the ATR neutron and gamma spectral influence on ${ }^{236} \mathrm{Pu}$. The pellet target was to examine the influcncc of $\mathrm{NpO}_{2}$ loading on ${ }^{236} \mathrm{Pu}$ and demonstrate pellet performance. The array target is planned to examine the influence of multi-target self shielding and provide data on the fission gas release from the pellet matrix. Finally, the prototype target are used to demonstrate/qualify prototype manufacturing methods and target quality control. To date, both the dosimeter targets and pellet targets have been irradiated in both ATR and HFIR and are undergoing post-irradiation examination (PIE). The ATR array targets will be fabricated and undergo partial irradiation this fiscal year. Future work in under consideration pending PIE results.

\subsubsection{Dosimeter Target Status}

All dosimeter targets from ATR were shipped back to ORNL for PIE. Several dosimeters have been analyzed and results are given in Table 1 .

Table 1. Preliminary analysis of selected dosimeter targets

\begin{tabular}{|c|c|c|c|}
\hline Reactor & Irradiation location & Environment & ${ }^{236} \mathrm{Pu}, \mathrm{ppm}^{(\mathrm{a})}$ \\
\hline ATR & Large B & Zircalloy & 1.5 \\
\hline ATR & Large B & Water & 1.5 \\
\hline ATR & Small B & Zircalloy & 2.3 \\
\hline ATR & Small B & Aluminum & 2.4 \\
\hline ATR & Small B & Water & 2.1 \\
\hline HFIR & Flux trap & Water & 2.0 \\
\hline HFIR & Small VXF & Water & 2.0 \\
\hline
\end{tabular}

(a) These results have not been adjusted back to discharge date.

The dosimeters listed in Table 1 were analyzed by conducting dissolution in glove boxes. However, the worker dose rate was significant enough to raise ALARA concerns. The remaining dosimeters have been moved to ORNL hot cell Building 2026 for PIE because of the dose rate. The low ${ }^{236} \mathrm{Pu}$ contents of these dosimeter targets is heartening.

\subsubsection{Pellet Targets Status}

\subsubsection{ATR Pellet Targets}

Pellet targets were discharged from the ATR, cooled for about thirty days, then shipped to ORNL using the GE-100 shipping cask. The targets were transferred into ORNL Building 2026 for PIE. The targets contained eight pellets-two pellets each at three different $\mathrm{NpO}_{2}$ vol\% loadings - 5, 10,20- as depicted in Figure 2. The targets were irradiated for one and two cycles with irradiation times varying from 49 to 111 days. The pellets used in this particular design are depicted at the top of Figure 3. As can be seen in the figure, the $\mathrm{NpO}_{2}$ is mixed with aluminum powder and encapsulated in a small aluminum clad. 

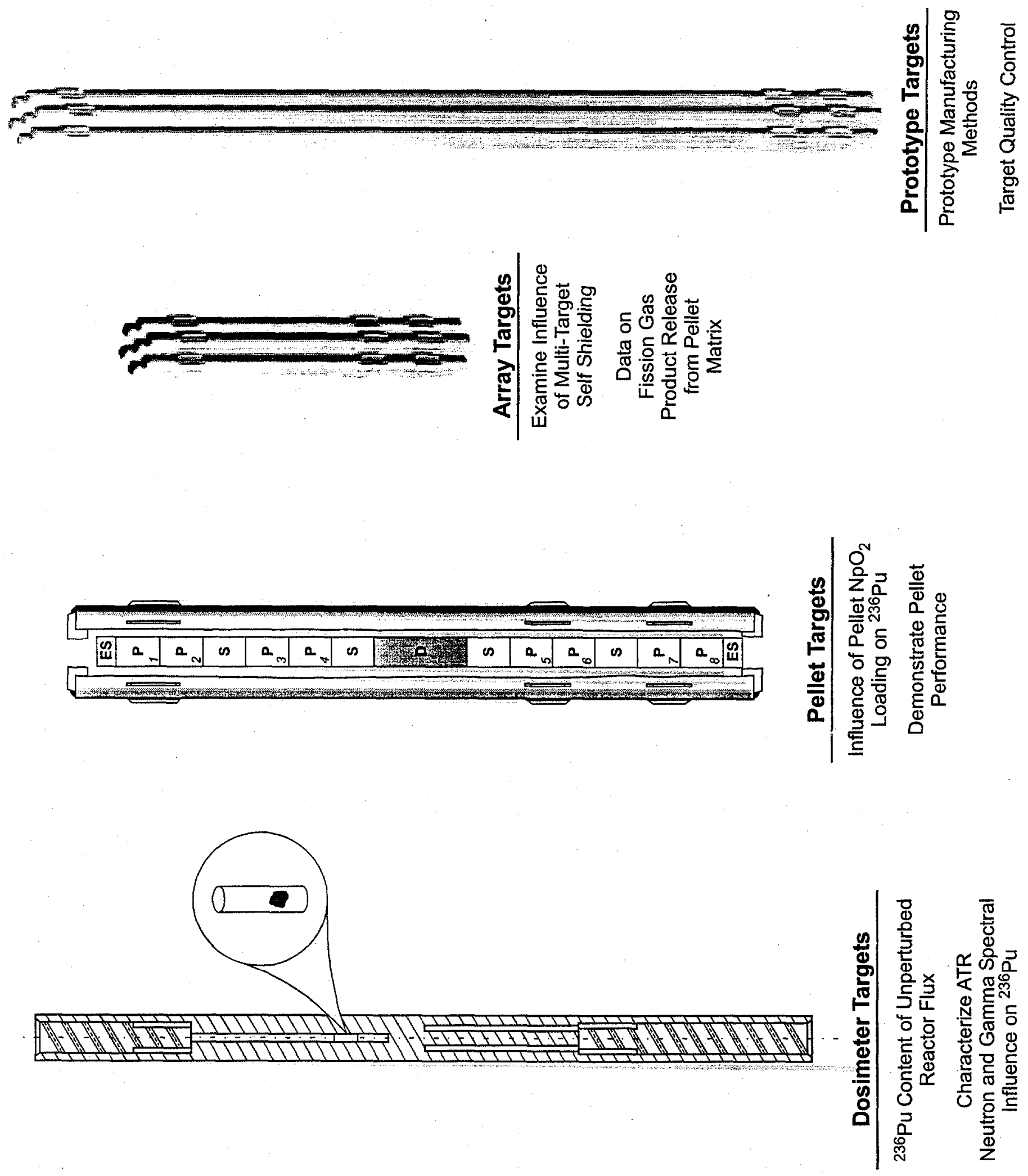


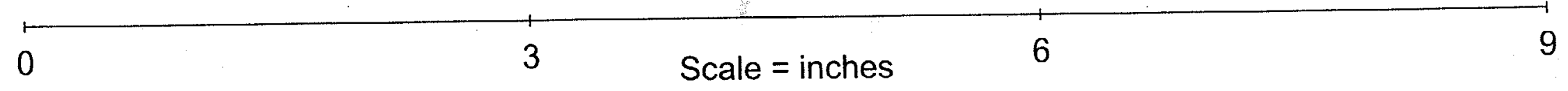

\section{Contents of Target}

\begin{tabular}{|l|c|c|c|c|c|c|c|c|c|c|c|c|c|c|}
\hline $\boldsymbol{w}$ & $\mathbf{P}$ & $\mathbf{P}$ & $\mathbf{S}$ & $\mathbf{P}$ & $\mathbf{P}$ & $\mathbf{S}$ & $\mathbf{D}$ & $\mathbf{S}$ & $\mathbf{P}$ & $\mathbf{P}$ & $\mathbf{S}$ & $\mathbf{P}$ & $\mathbf{P}$ & $\mathbf{\Psi}$ \\
\hline
\end{tabular}

Vol \%

Pellet $(P)=0.571$ in.

Spacer $(S)=0.62$ in.

Dosimeter package $(D)=1.5 \mathrm{in}$.

Endspacer $(E S)=0.25$ in.

\section{Pellet}

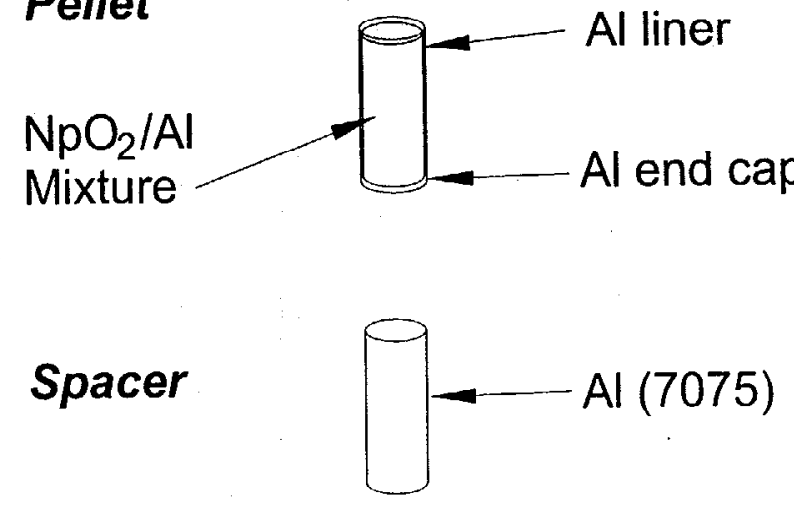

Note: All diameters are 0.25 in.

\section{Dosimeter Package}

Zr-4 Bar Stock

11

Fig. 2. Preconceptual Target Design. 


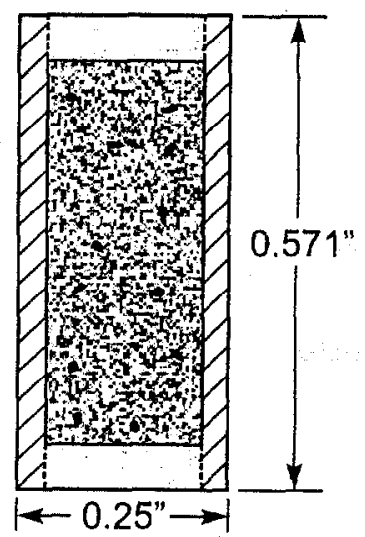

Clad Pellet for ATR

Pellet Targets

$\mathrm{NpO}_{2}$ content: $0.1-0.4 \mathrm{~g}$

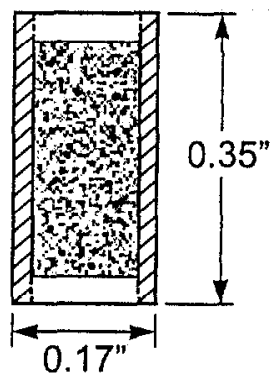

Clad Pellet for HFIR

Pellet Targets

$\mathrm{NpO}_{2}$ content: $0.05-0.1 \mathrm{~g}$

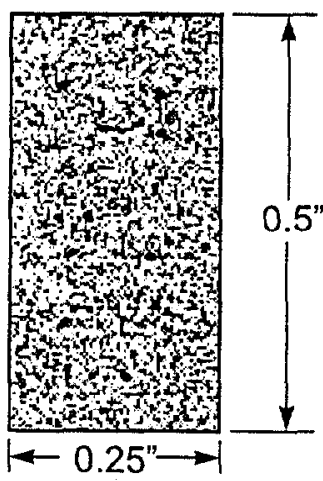

Bare Pellet for ATR

Array Targets

$\mathrm{NpO}_{2}$ content: $0.4-0.8 \mathrm{~g}$

Fig. 3. Clad and bare neptunium oxide pellets for ATR and HFIR. 
Examination of the irradiated targets received from ATR indicated that they had sustained damage on the end caps. Photographs were taken of the end caps and sent to INEEL for review. A representative of INEEL visited ORNL for a visual check of the targets. After these reviews, the INEEL groups conducted that the damage was mechanical damage occurring after discharge form the reactor. Additional photos will be taken for archival purposes prior to dissolution of the target ends. In order to prevent damage to future targets, another step has been added to the overall process. Additional photos will be taken to document conditions of the targets at various points during the fabrication-irradiationshipping-PIE process.

The ATR pellet targets were then segmented in order to dissolve the various pellet combinations for chemical analysis. Figure 4 depicts the general flowsheet for chemical analysis. Figure 5 is a photograph showing the equipment used in the hot cell for dissolution. Several of the pellets have been dissolved and analyzed. Those results are presented in Table 2 .

Table 2. Preliminary results from selected pellets irradiated in the ATR

\begin{tabular}{|c|c|c|c|}
\hline \multirow{2}{*}{ Target number } & \multirow{2}{*}{ Pellet number(s) } & Predicted & Measured \\
\cline { 3 - 4 } & & 0.909 & 0.906 \\
\hline Np-006 & Np-2, Np-3 & 0.935 & 0.917 \\
\hline Np-005 & Np-35, Np-36 & 0.904 & 0.885 \\
\hline Np-005 & Np-8 & 0.800 & 0.792 \\
\hline Np-003 & Np-24, Np-25 & 0.850 & 0.814 \\
\hline Np-003 & Np-4, Np-5 & 0.790 & 0.858 \\
\hline Np-004 & Np-6, Np-7 & 0.846 & 0.866 \\
\hline Np-007 & Np-28, Np-37 & & \\
\hline
\end{tabular}

Chemical analysis of pellets will continue with additional dissolutions and determination of ${ }^{236} \mathrm{Pu}$ coritent.

After the bulk of the dissolutions are complete, selected pellets will be transferred to hot cell Building 3525 for metallography. The general flowsheet for metallography is shown in Fig. 6. Results from this examination are expected to show melting, if any, and interaction between the $\mathrm{NpO}_{2}$ and Al.

\subsubsection{HFIR Pellet Targets}

HFIR pellets were smaller than the ATR pellets, as depicted in Figure 3. These pellets were designed for a very conservative heat generation rate of about $250,000 \mathrm{BTU} / \mathrm{hr} . \mathrm{ft}^{2}$ due to time and budget limitations.

HFIR targets were irradiated, cooled, and transferred to Building 2026. A set of four dissolutions have been completed. Analytical results are not complete at this time but are expected during the next quarter.

\subsubsection{Array Targets}

The next phase of the target development is design, fabrication, irradiation, and PIE of array targets as depicted in Figure 1. The pellets for the array targets are closer in resemblance to production type pellets rather than the clad pellets. The pellets are depicted at the bottom of Figure 3 . The pellets are made by mixing aluminum powder with $\mathrm{NpO}_{2}$ powder, pouring the mixture into a pellet die, and compressing it to $30 \%$ of theoretical density. 


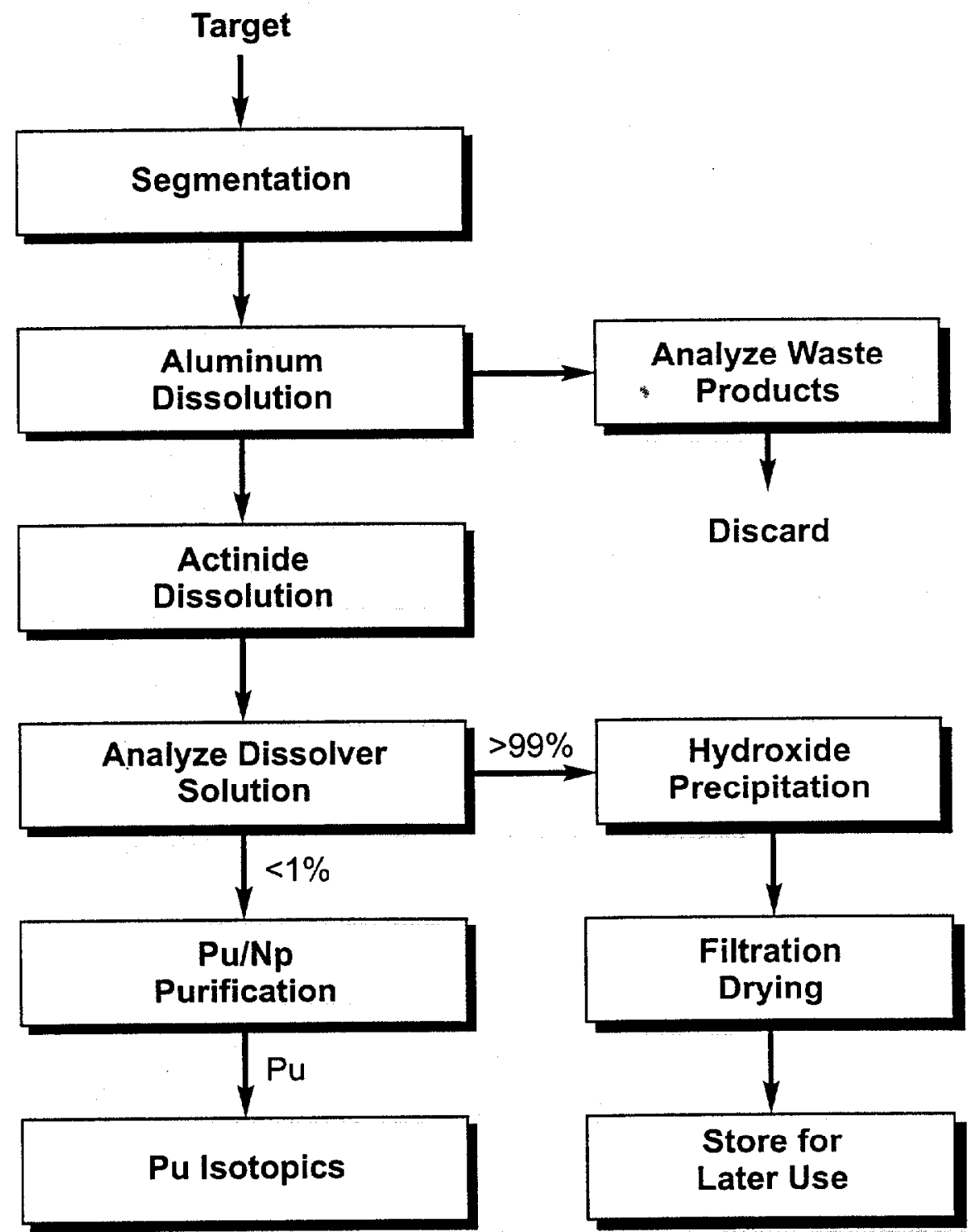

Fig. 4. Chemical analysis of pellets will provide both burnup data and $\mathrm{Pu}$ isotopics data. 


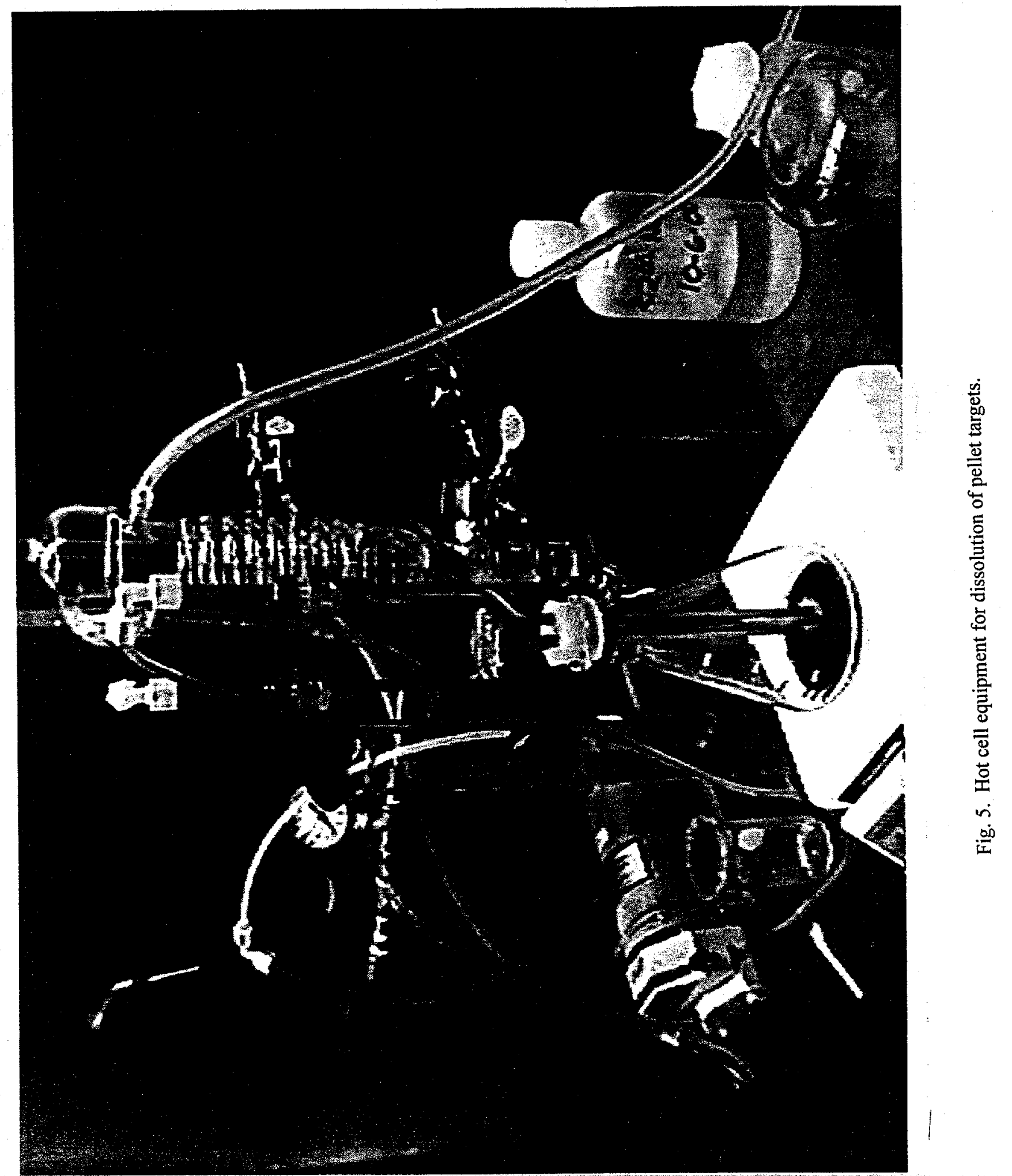




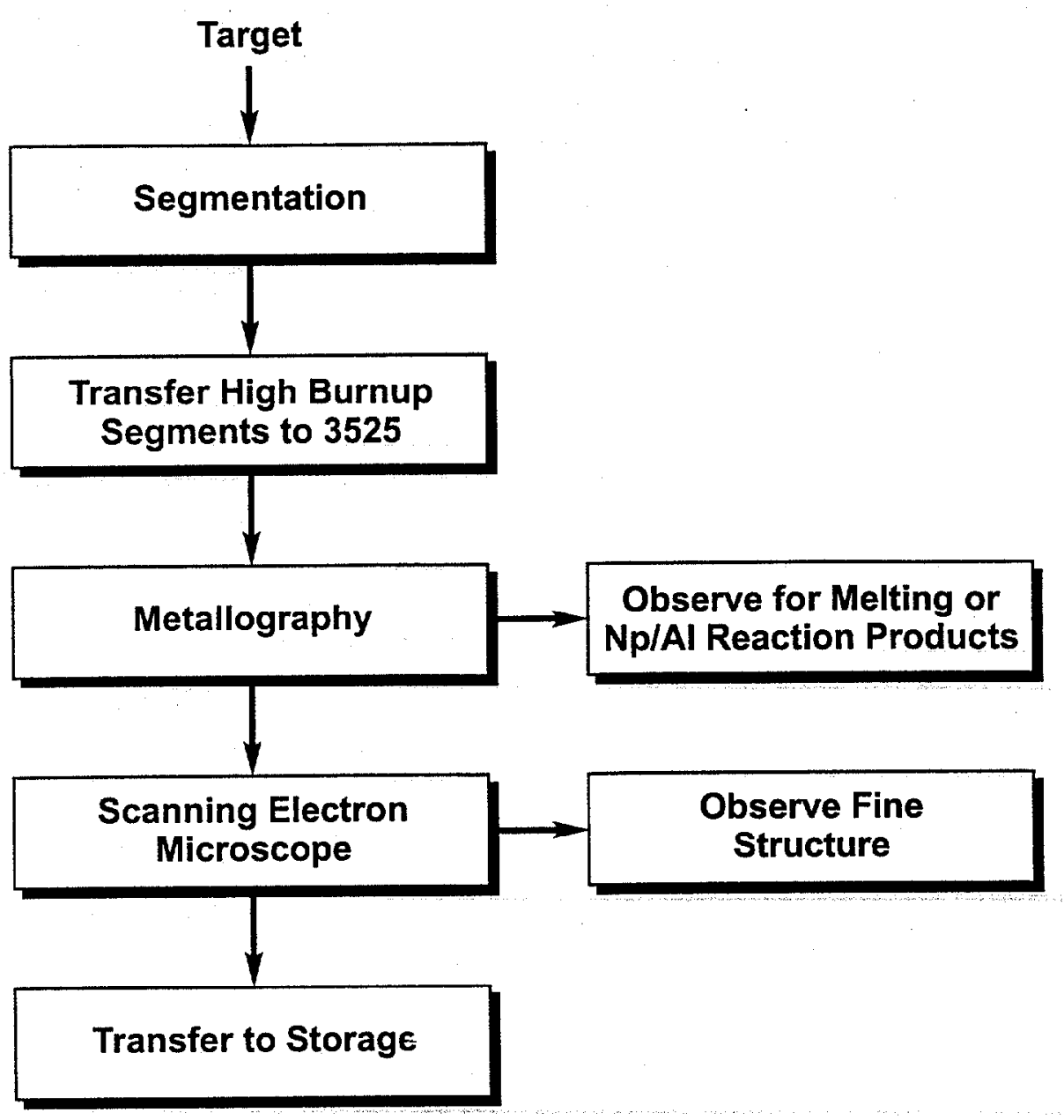

Fig. 6. Metallography will be used to assess pellet performance for selected pellets. 
The design requirements for the array targets in decreasing priority are as follows:

1. Two levels of neptunium loading should be used to establish a range.

2. Product plutonium should be $\sim 85 \% \mathrm{Pu}-238$ to give a product yield close to that anticipated for production.

3. Fission gas pressurc must be kept lower than the allowable ASME Class III standards for reactor components fabricated with aluminum ( $\sim 270 \mathrm{psi}$ internal gas pressure).

4. Total plutonium at end of irradiation must be less than $60 \mathrm{Ci}$ in order to transport the targets in three GE-100 shipments.

Item 1 was dealt with by establishing 10 vol\% and 20 vol\% loading for the $\mathrm{NpO}_{2} / \mathrm{Al}$ matrix. These loadings are expected to be in the range of practical loadings for production targets.

Item 2 was dealt with by splitting the target into two separate targets in order to optimize the exposure of both the 10 vol $\%$ pellets and 20 vol\% pellets. The initial target, as designed, would not allow optimization of the ${ }^{238} \mathrm{Pu}$ product at $\sim 85 \%{ }^{238} \mathrm{Pu}$ /total plutonium. However, this increased target fabrication efforts by requiring fabrication of an additional seven targets.

Item 3 was dealt with by adding void space for fission gas release. This is readily accommodated for experimental targets but could not be used for production targets due to a substantial increase in target length. The target was also redesigned to allow gas sampling of the void space as part of the PIE. The data on fission gas release will be necessary for design of prototype and production targets.

Item 4 was dealt with by limiting the initial change of neptunium to each target in order to ensure that the final plutonium content would be under $60 \mathrm{Ci}$ total.

Figure 7 depicts the current planned design for the array targets. There will be fourteen targets fabricated containing a total of three pellets where the pellet $\mathrm{NpO}_{2}$ loading is either $10 \mathrm{vol} \%$ or $20 \mathrm{vol} \%$. There has been a special gas plenum added on to allow post irradiation sampling of the fusion gas release from the target matrix. It is anticipated that data on fission gas release will allow subsequent target designs to substantially reduce the gas plenum.

Several bare pellets were fabricated using $\mathrm{CeO}_{2}$ as a cold stand in for $\mathrm{NpO}_{2}$. Problems were encountered with the proper addition of lubricant to the dies and with extracting of the pellet out of the die. Modifications to the pellet pressing procedure were made based on the $\mathrm{CeO}_{2} / \mathrm{Al}$ pellet work. Additional $\mathrm{CeO}_{2}$ pellets were successfully pressed for fabrication of a cold target mockup. The procedure for pressing $\mathrm{NpO}_{2}$ pellets was modified based on the results of the cold pressing. The $\mathrm{CeO}_{2}$ pellets were assembled into a target and to verify additional target fabrication techniques prior to $\mathrm{NpO}_{2} / \mathrm{Al}$ pellet pressing.

All forty-two pellets for the array target have been fabricated during this reporting period. Target but bodies have been heat treated to the $\mathrm{T} 4$ condition and are undergoing additional machining prior to assembly.

\subsection{CONCEPTUAL PLANNING}

\subsubsection{PEIS Support}

During this reporting period, ORNL staff provided detailed reviews and comments on the ORNL portion of the PEIS. ORNL staff also attended a PEIS review meeting in Germantown Oct 31 to Nov 2.

\subsubsection{Program Planning Document}

A draft table of contents for a report titled "Preliminary Project Plan for Reestablishing Domestic ${ }^{238}$ Pu Production" has been developed and transmitted for DOE for review. 

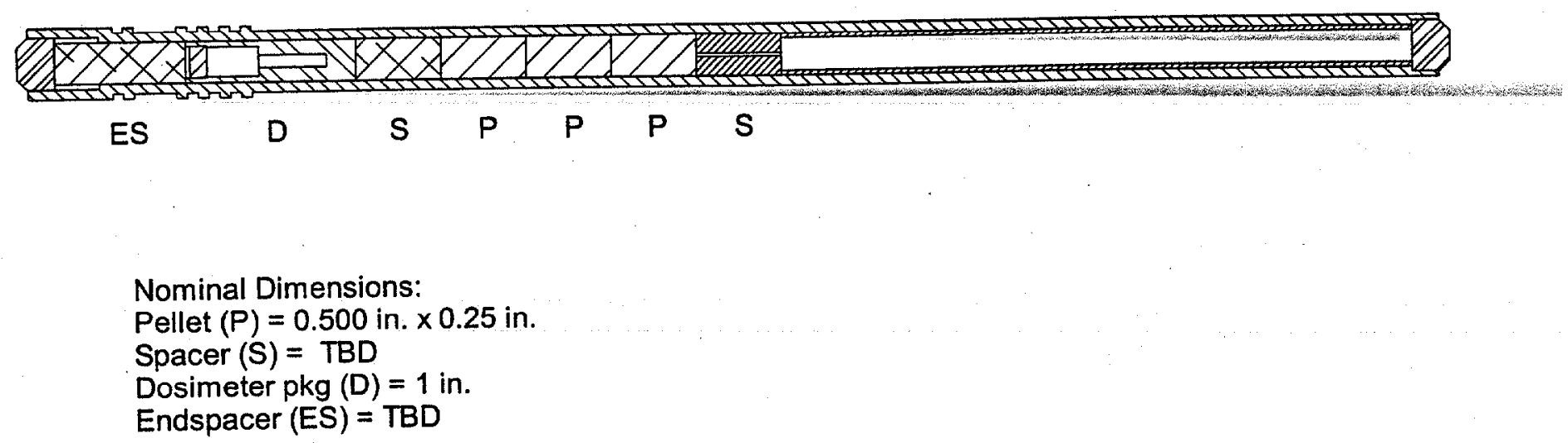

Fig. 7. Current conceptual design of ATR array target.

\subsubsection{Target Fabrication Support}

The safety analyses for ATR and HFIR target irradiation have pointed out several weak spots in current target documentation. These are areas where specific data on the proposed target design(s) have not been developed and the safety analyst must rely on other published or worst-case assumptions which are more conservative and limit the target loading. Examples of these areas are (1) thermal conductivity of $\mathrm{NpO}_{2} / \mathrm{Al}$ mixtures, (2) materials of construction (specifically X8001 loading, (4) fission gas release from the target matrix. Items 1 and 3 are to be evaluated during the fiscal year.

\subsubsection{Thermal Conductivity}

This effort will be based on preparing small cylinders of cerium oxide mixed with aluminum pressed to $90 \%$ of theoretical density. In this case, cerium oxide is used as a cold stand in for neptunium oxide due to equipment contamination concerns. Several pieces have been pressed and tested. For best results, the pieces must yield characteristic heat transfer times within the range of times analyzed by the equipment. Results to date indicate our pieces are larger than optimum and new pieces will be required. These pieces will be fabricated after the array target fabrication.

\subsubsection{Target Loading Quality Control}

Homogeneity of each pellet is currently ensured by radiography and destructive evaluation of selected pellets. The desire is to move to a non-destructive technique amenable to rapid turnaround times and high throughput. Initial concepts are based on gamma scan to look at ${ }^{233} \mathrm{~Pa}$ and helium leak tests. INEEL staff will be at ORNL in May 2001 for review of initial concepts.

\subsubsection{Neptunium Oxide Transfer Plans}

The general approach to $\mathrm{NpO}_{2}$ transfer from SRS is depicted in Fig. 8. Neptunium currently in solution will be converted to an oxide in HB Phase II glove box line. The oxide will be transferred to a can and a lid will be crimpsealed on top. The can will be bagged out of the glove box and placed into a slightly larger crimp-sealed can. The resulting can will be transferred into either a 9975 or $6 \mathrm{M}$ shipping package for subsequent shipment to Oak Ridge. Discussions have been held with SRS staff concerning the anticipated timing and loading. SRS has also supplied an example of a shipper/receiver agreement. More discussions with SRS staff are anticipated. 


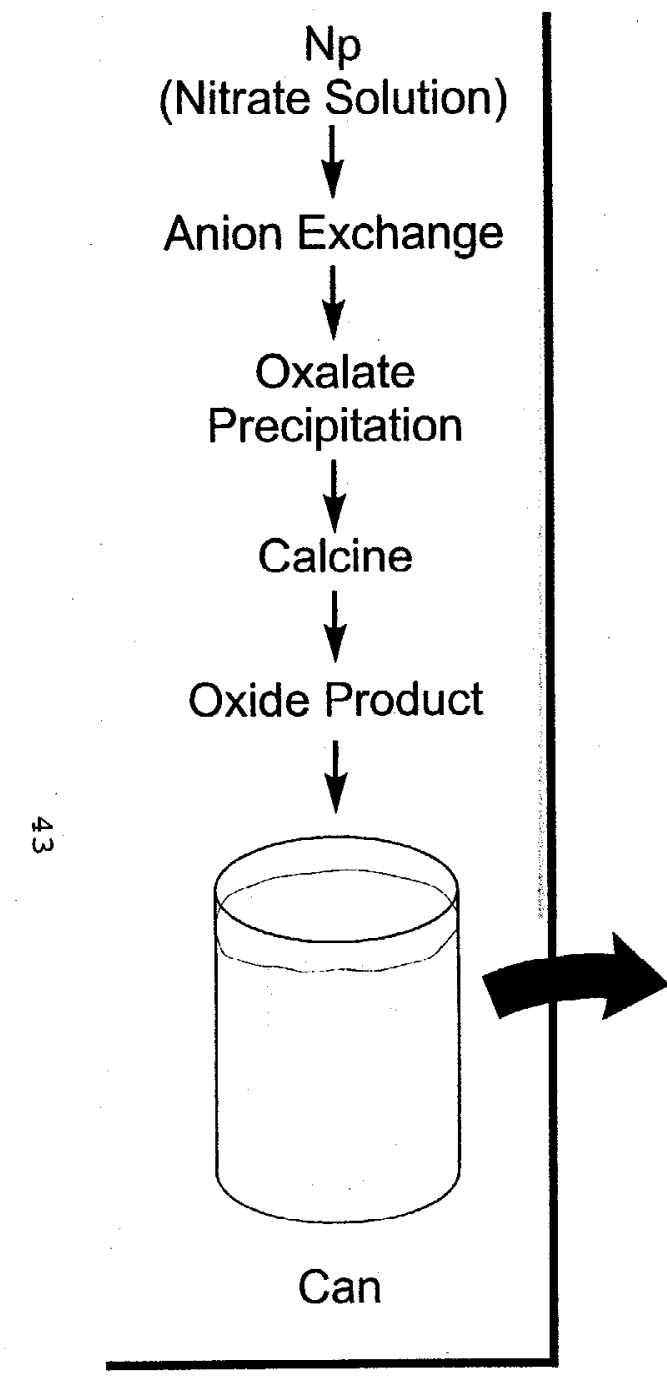

Glove Box

Confinement
Assume density of $2 \mathrm{~g} / \mathrm{cc}$

Assume 800-1200 $\mathrm{g} \mathrm{NpO}_{2} /$ batch

1 batch/can
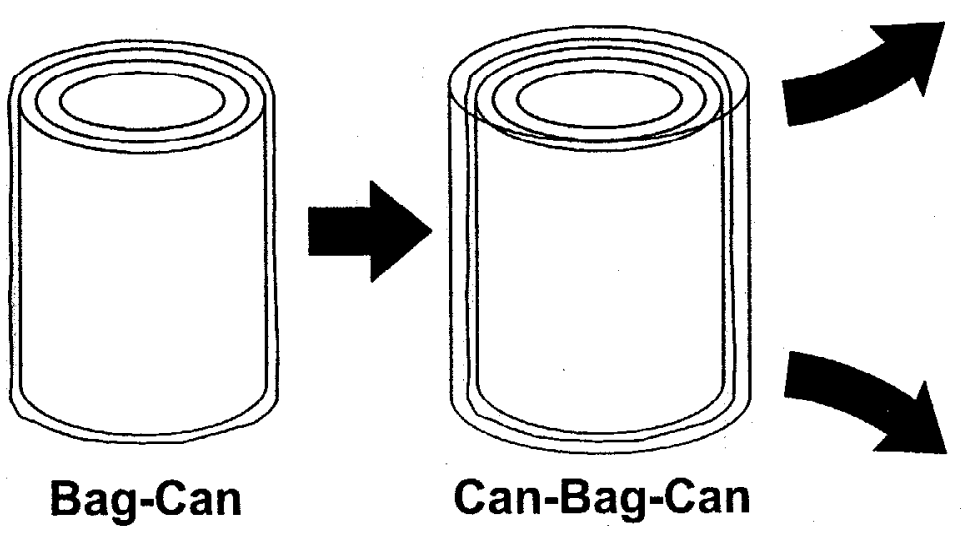

Can-Bag-Can

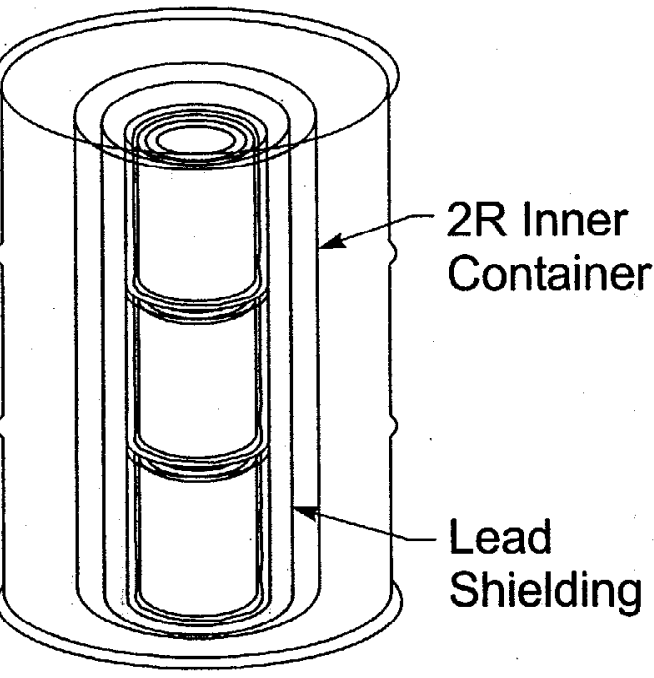

6M Drum (30 gal)

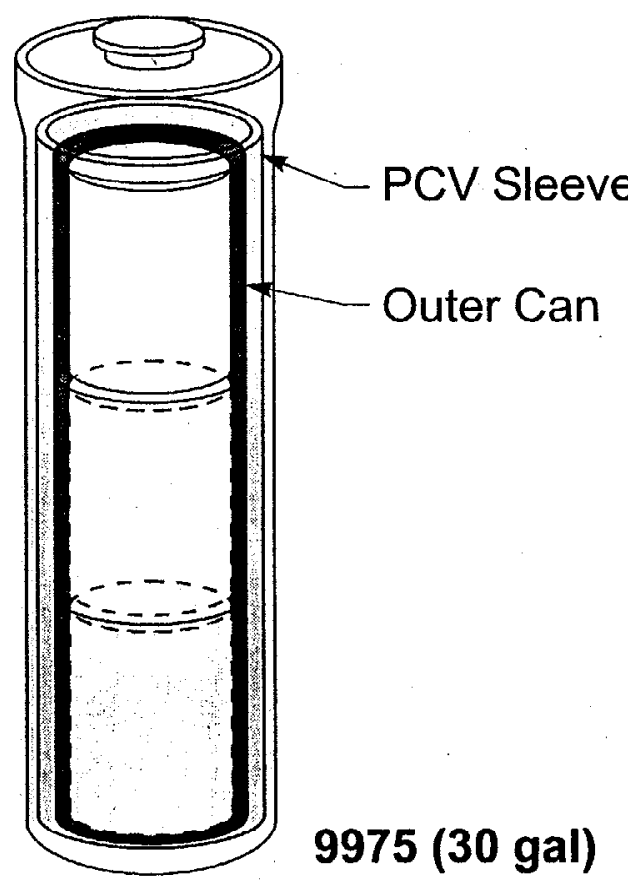




\section{INTERNAL DISTRIBUTION}

1. E. P. George

2. J. S. Ivey

3. J. F. King

4. C. G. McKamey

5-7. J. P. Moore

8. E. K. Ohriner
9. G. R. Romanoski

10. G. B. Ulrich

11. M. C. Vance

12. R. M. Wham

13. Laboratory Records

\section{EXTERNAL DISTRIBUTION}

14-22. U. S. DEPARTMENT OF ENERGY, NE-50, Germantown Building, 11901 Germantown Road, Germantown, MD 20874-1290
C. E. Brown
J. Dowicki
A. S. Mehner
L. W. Edgerly
R. C. Raczynski
R. R. Furlong
L. L. Rutger
E. J. Wahlquist

L. C. Herrera

23. DEPARTMENT OF ENERGY, Albuquerque Field Office, P.O. Box 5400, Albuquerque, NM 87115

R. L. Holton

24-25. DEPARTMENT OF ENERGY, Oak Ridge Operations Office, Bldg. 4500N, Oak Ridge, TN 37831

L. W. Boyd, Mail Stop 6390

S. R. Martin, Jr., Mail Stop 6269

26. DEPARTMENT OF ENERGY, Los Alamos Area Office, 528 35th Street, Los Alamos, NM 87544

R. J. Valdez

27. DEPARTMENT OF ENERGY, Savannah River Operations Office, Bldg. 703F, P.O. Box A, Aiken, SC 29802

S. W. McAlhaney

28. DEPARTMENT OF ENERGY, Miamisburg Óffice, P.O. Box 66, Miamisburg, OH 45342

T. A. Frazier

29. BABCOCK AND WILCOX OF OHIO, INC., 1 Mound Road, Miamisburg, $\mathrm{OH} 45343-3000$

D. M. Gabriel

30. LOCKHEED MARTIN ASTRONAUTICS, P.O. Box 8555, Philadelphia, PA 19101

R. M. Reinstrom 
31. LOS ALAMOS NATIONAL LABORATORY, P.O. Box 1663, NMT-9, MS E502,

Los Alamos, NM 87545

E. M. Foltyn

32. TETRA TECH NUS INC., 910 Clopper Road, Suite 400

Gaithersburg, MD 20878-1399

B. W. Bartram

33-34. ORBITAL SCIENCES CORPORATION, INC., 20301 Century BIvd., Germantown, MD 20874

R. T. Carpenter

E. A. Skrabek

35. PHILLIPS LABORATORY, Kirtland Air Force Base, AFRL/VSDV, 3550

Aberdeen Avenue SE, NM 87117

C. Mayberry

36. TEXAS A\&M UNIVERSITY, Center for Space Power, Mail Stop 3118, College Station, TX 77843

M. J. Schuller

37. WESTINGHOUSE ADVANCED TECHNOLOGY BUSINESS AREA,

P.O. Box 355, Pittsburgh, PA 15230-0355

M. O. Smith

38. WESTINGHOUSE SAVANNAH RIVER COMPANY, Savannah River Site, Aiken, SC 29808

R. W. Saylor 